\title{
A resonance Raman spectroscopic and CASSCF investigation of the Franck-Condon region structural dynamics and conical intersections of thiophene
}

\author{
Xian-Fang Wu, ${ }^{1}$ Xuming Zheng, ${ }^{1, a), b)}$ Hui-Gang Wang, ${ }^{1}$ Yan-Yin Zhao, ${ }^{1}$ Xiangguo Guan, ${ }^{2}$ \\ David Lee Phillips, ${ }^{2, a), c)}$ Xuebo Chen, ${ }^{3}$ and Weihai Fang ${ }^{3, a), d)}$ \\ ${ }^{1}$ Department of Chemistry and Key Laboratory of Advanced Textiles Material and Manufacture Technology, \\ MOE, Zhejiang Sci-Tech University, Hangzhou 31008, People's Republic of China \\ ${ }^{2}$ Department of Chemistry, University of Hong Kong, Pokfulam Road, Hong Kong, People's Republic of \\ China \\ ${ }^{3}$ Department of Chemistry, Beijing Normal University, Xin-wai-da-jie No. 19, Beijing 100875, People's \\ Republic of China
}

(Received 31 January 2010; accepted 25 July 2010; published online 7 October 2010)

\begin{abstract}
Resonance Raman spectra were acquired for thiophene in cyclohexane solution with 239.5 and 266 $\mathrm{nm}$ excitation wavelengths that were in resonance with $\sim 240 \mathrm{~nm}$ first intense absorption band. The spectra indicate that the Franck-Condon region photodissociation dynamics have multidimensional character with motion mostly along the reaction coordinates of six totally symmetry modes and three nontotally symmetry modes. The appearance of the nontotally symmetry modes, the $\mathrm{C}-\mathrm{S}$ antisymmetry stretch $+\mathrm{C}-\mathrm{C}=\mathrm{C}$ bend mode $\nu_{21}\left(\mathrm{~B}_{2}\right)$ at $754 \mathrm{~cm}^{-1}$ and the $\mathrm{H}_{7} \mathrm{C}_{3}-\mathrm{C}_{4} \mathrm{H}_{8}$ twist $\nu_{9}\left(\mathrm{~A}_{2}\right)$ at $906 \mathrm{~cm}^{-1}$, suggests the existence of two different types of vibronic-couplings or curve-crossings among the excited states in the Franck-Condon region. The electronic transition energies, the excited state structures, and the conical intersection points ${ }^{1} \mathrm{~B}_{1} /{ }^{1} \mathrm{~A}_{1}$ and ${ }^{1} \mathrm{~B}_{2} /{ }^{1} \mathrm{~A}_{1}$ between $2{ }^{1} \mathrm{~A}_{1}$ and $1{ }^{1} \mathrm{~B}_{2}$ or $1{ }^{1} \mathrm{~B}_{1}$ potential energy surfaces of thiophene were determined by using complete active space self-consistent field theory computations. These computational results were correlated with the Franck-Condon region structural dynamics of thiophene. The ring opening photodissociation reaction pathway through cleavage of one of the $\mathrm{C}-\mathrm{S}$ bonds and via the conical intersection point ${ }^{1} \mathrm{~B}_{1} /{ }^{1} \mathrm{~A}_{1}$ was revealed to be the predominant ultrafast reaction channel for thiophene in the lowest singlet excited state potential energy hypersurface, while the internal conversion pathway via the conical intersection point ${ }^{1} \mathrm{~B}_{2} /{ }^{1} \mathrm{~A}_{1}$ was found to be the minor decay channel in the lowest singlet excited state potential energy hypersurface. () 2010 American Institute of Physics. [doi:10.1063/1.3480361]
\end{abstract}

\section{INTRODUCTION}

Thiophene is a simple five-membered heterocyclic molecule $^{1}$ and a fundamental building block to form thiophene-based materials such as oligothiophene polymers, ${ }^{2,3}$ semiconductors, ${ }^{4}$ nonlinear optics, ${ }^{5}$ and photochromic materials. ${ }^{6}$ Many experimental and theoretical investigations have been done to study and characterize the electronic structures, photochemistry, and ultrafast excited state reaction dynamics of thiophene and thiophene-based materials. ${ }^{7-32}$ The gas phase UV absorption spectrum of thiophene in the lowest valence state (an A-band located at $5.5 \mathrm{eV}$ ) has a long vibrational progression with the lowest absorption at $41595 \mathrm{~cm}^{-1}(5.15 \mathrm{eV})$ that has been attributed to the vibrational origin of the $1{ }^{1} \mathrm{~A}_{1} \rightarrow 2{ }^{1} \mathrm{~A}_{1}$ or $\pi \rightarrow \pi^{*}$ transition. ${ }^{8-10}$ The gas phase UV absorption spectrum confirms the valence nature of the strong bands at 5.5 and 7.0

\footnotetext{
a) Authors to whom correspondence should be addressed.

${ }^{b)}$ Tel.: 86-571-86843699. FAX: 86-571-86843702. Electronic mail: zxm@zstu.edu.cn.

${ }^{c}$ Tel.: 852-2859-2160. FAX: 852-2857-1586. Electronic mail: phillips@hkucc.hku.hk.

${ }^{d)}$ Electronic mail: fangwh@bnu.edu.cn.
}

$\mathrm{eV}^{9,11-13}$ The magnetic circular dichroism spectrum of thiophene in hexane solution exhibits two bands at 5.27 and $5.64 \mathrm{eV}$, respectively. ${ }^{14,15}$ Two low-lying ${ }^{3}\left(\pi, \pi^{*}\right)$ states were observed at about 3.7 and $4.6 \mathrm{eV}$ in electron energy-loss spectra. ${ }^{16-18}$ The excited states of thiophene have been characterized by a number of experimental measurements ${ }^{9,16-19}$ and $a b$ initio calculations. ${ }^{9,19-21}$ Bendazzoli and co-workers assigned experimental $\tilde{\mathrm{A}}\left(41595 \mathrm{~cm}^{-1} / 240 \mathrm{~nm} / 5.15 \mathrm{eV}\right)$, $\mathrm{B}\left(48330 \mathrm{~cm}^{-1} / 206 \mathrm{~nm} / 5.99 \mathrm{eV}\right)$, and $\mathrm{C}\left(53270 \mathrm{~cm}^{-1 /}\right.$ $188 \mathrm{~nm} / 6.60 \mathrm{eV}$ ) absorptions as the origins of the $2{ }^{1} \mathrm{~A}_{1}$, $1{ }^{1} \mathrm{~B}_{1}$, and $1{ }^{1} \mathrm{~B}_{2}$ states, and the two bands at 30250 and $37270 \mathrm{~cm}^{-1}$ (from Refs. 16-18) as being due to the $1^{3} \mathrm{~B}_{2}$, and $1{ }^{3} \mathrm{~A}_{1}$ triplet states, respectively. High level multireference multiroot CI computations by Palmer et al. ${ }^{19}$ indicated that the two strong absorption bands centered at the calculated 5.5 and $7.0 \mathrm{eV}$ energies were due to the $1{ }^{1} \mathrm{~A}_{1}$ $\rightarrow 2{ }^{1} \mathrm{~A}_{1}$ and $1{ }^{1} \mathrm{~A}_{1} \rightarrow 1{ }^{1} \mathrm{~B}_{2}$ transitions, respectively. The two triplet states situated energetically below the $2{ }^{1} \mathrm{~A}_{1}$ state, $1{ }^{3} \mathrm{~B}_{2}$ and $1{ }^{3} \mathrm{~A}_{1}$, were also confirmed by recent work. ${ }^{20,21} \mathrm{~A}$ CASPT2 calculation study of the excited states of thiophene results in the two strong absorption bands centered at 6.79 and $7.29 \mathrm{eV}^{22}$ Combined density functional/multireference 
configuration interaction method (DFT/MRCI) calculations were utilized to examine the ground state and low-lying electronic excited states of thiophene. ${ }^{23}$ This work predicted the $1{ }^{1} \mathrm{~A}_{1} \rightarrow 2{ }^{1} \mathrm{~A}_{1}$ and $1{ }^{1} \mathrm{~A}_{1} \rightarrow 1{ }^{1} \mathrm{~B}_{2}$ transitions to be at 5.39 and $5.54 \mathrm{eV}$ with the corresponding oscillator strengths being 0.1142 and 0.1121 , respectively, ${ }^{23}$ with the latter assignment being different from that of a previous study (see Ref. 19). It appears that almost all of the previous assignments agree that the low-lying intense transition at $41595 \mathrm{~cm}^{-1}$ $(5.15 \mathrm{eV})$ is the vibrational origin of the $1{ }^{1} \mathrm{~A}_{1} \rightarrow 2{ }^{1} \mathrm{~A}_{1}$ transition. The vibronic structure of the UV spectrum of thiophene was studied by several research groups. ${ }^{24}$ The $965 \mathrm{~cm}^{-1}$ progression was found to dominate the absorption spectrum due to $1083 \mathrm{~cm}^{-1}$ vibration. According to our present study, the $1083 \mathrm{~cm}^{-1}$ mode is the $\nu_{5}$ vibration. The other relevant ground state frequencies were found to be $839 \mathrm{~cm}^{-1}\left(\nu_{3}\right), \quad 1036 \mathrm{~cm}^{-1}\left(\nu_{6}\right), \quad 608 \mathrm{~cm}^{-1}\left(\nu_{8}\right)$, $565 \mathrm{~cm}^{-1}\left(\nu_{11}\right), 452 \mathrm{~cm}^{-1}\left(\nu_{14}\right)$, and $751 \mathrm{~cm}^{-1}\left(\nu_{21}\right){ }^{10}$

Nucleophilic aromatic photosubstitution reactions of thiophenes substituted with iodine or bromine atoms and electron withdrawing groups in the presence of aromatic compounds have been characterized by steady state and laser flash photolysis experiments. ${ }^{25}$ A reaction mechanism proposed by D'Auria and co-workers ${ }^{26,27}$ suggested that the initially excited thiophenes undergo intersystem crossing (ISC) to a triplet state $\left(\pi-\sigma^{*}, \mathrm{n}-\sigma^{*}\right.$, or $\left.\sigma-\sigma^{*}\right)$ mainly localized on the carbon-iodine bond and the resulting thiophene triplet state interacts with the aromatic compounds to result in homolytic cleavage of the $\mathrm{CI}$ bond to produce a thienyl radical that subsequently reacts very fast with the aromatic compound to produce the corresponding arylation product. ${ }^{28}$ Photochemical isomerization reactions of thiophene and its derivatives have also been characterized by $a b$ initio $^{29}$ and complete active space self-consistent field (CASSCF) calculations ${ }^{30}$ that examined the reaction channels for the photoisomerization of 2-methylthiophene to 3-methylthiophene on the ground state $\left(\mathrm{S}_{0}\right)$ and lowest triplet excited state potential energy surfaces.

The ultrafast internal conversion and photodissociation dynamics of thiophene in the first excited state was recently examined by femtosecond pump probe photoelectron spectroscopy and combined density functional/multireference configuration interaction (DFT/MRCI) computations ${ }^{23,31}$ and a linear vibronic-coupling scheme was invoked to help interpret the photophysics. ${ }^{32}$ The femtosecond pump probe photoelectron spectroscopy experiments observed two time constants relative to the very early excited state dynamics and these time constants were attributed to the vibrational dynamics in the first excited state $(80 \pm 10 \mathrm{fs})$ and an ultrafast decay via a conical intersection thought to lead to a ring opening in the $1{ }^{1} \mathrm{~B}_{1}$ state $(25 \pm 10 \mathrm{fs}){ }^{31}$ The global minimum structure of the $1{ }^{1} \mathrm{~B}_{1}$ state is predicted theoretically to exhibit an asymmetric planar nuclear arrangement with one significantly elongated $\mathrm{C}-\mathrm{S}$ bond. ${ }^{23}$ The minimum energies of the six conical intersections between the $2{ }^{1} \mathrm{~A}_{1}, 1{ }^{1} \mathrm{~A}_{2}$, $1{ }^{1} \mathrm{~B}_{2}, 1{ }^{1} \mathrm{~B}_{1}$ and $1{ }^{1} \mathrm{~A}_{2}, 1{ }^{1} \mathrm{~B}_{2}, 1{ }^{1} \mathrm{~B}_{1}$ states were determined using a linear vibronic-coupling model. ${ }^{32}$

In this paper we report a combined resonance Raman spectroscopic and CASSCF computational investigation of the excited state structural dynamics of thiophene. The $239.5 \mathrm{~nm}$ resonance Raman spectra of thiophene in cyclohexane solution probes the potential energy surface of the transition allowed $\pi_{2} \rightarrow \pi_{4}{ }^{*}$ or $1{ }^{1} \mathrm{~A}_{1} \rightarrow 2{ }^{1} \mathrm{~A}_{1}$ transition for the $\sim 232 \mathrm{~nm}$ intense absorption band. Density functional theory and CASSCF computations were done to predict the geometry structures, the energy levels and the vibrational frequencies for ground and electronic excited states, as well as to search for conical intersections between the $2{ }^{1} \mathrm{~A}_{1}$ and other excited states for thiophene. This work suggests that there are two strong vibronic-couplings, one is between $2{ }^{1} \mathrm{~A}_{1}$ and $1{ }^{1} \mathrm{~B}_{1}$ through vibrational motions along the antisymmetry $\mathrm{C}-\mathrm{S}$ stretch $+\mathrm{C}-\mathrm{C}=\mathrm{C}$ bend mode $\nu_{21}$ and the $\mathrm{C}-\mathrm{H}$ in-plane wag $\nu_{18}$ mode, and the other is between $2{ }^{1} \mathrm{~A}_{1}$ and $1{ }^{1} \mathrm{~B}_{2}$ via vibrational motion along the $\mathrm{H}_{7} \mathrm{C}_{3}-\mathrm{C}_{4} \mathrm{H}_{8}$ twist.

\section{EXPERIMENTAL AND COMPUTATIONAL METHODS}

\section{A. Resonance Raman experiments}

The resonance Raman experimental methods and apparatus have been described previously ${ }^{33-36}$ so only a short description will be provided here. The harmonics of a nanosecond Nd:YAG laser and their hydrogen Raman shifted laser lines were employed to generate the 239.5 and $266 \mathrm{~nm}$ excitation wavelengths utilized in the resonance Raman experiments. Concentrations of approximately $0.013 \mathrm{M}-$ $0.025 \mathrm{M}$ thiophene (99\% purity) in spectroscopic grade cyclohexane $(99.5+\%$ purity) solvent were used to prepare sample solutions. The excitation laser beam used a $\sim 100 \mu \mathrm{J}$ pulse energy loosely focused to a $0.5-1.0 \mathrm{~mm}$ diameter spot size onto a flowing liquid stream of sample to excite the sample. Power-dependent experiments were done using $\sim 100 \mu \mathrm{J}$ pulse energy focused on a beam diameter of $\sim 1.0 \mathrm{~mm}$ and $\sim 260 \mu \mathrm{J}$ pulse energy focused on a beam diameter of $\sim 0.5 \mathrm{~mm}$, respectively. No power-dependent Raman peaks were found within the test conditions and this indicated that there were no noticeable transients or photoproducts contributed to the resonance Raman spectra. A backscattering geometry was employed for collection of the Raman scattered light by reflective optics that imaged the light through a polarizer and entrance slit of a $0.5 \mathrm{~m}$ spectrograph and the grating of the spectrograph dispersed the light onto a liquid nitrogen cooled CCD mounted on the exit of the spectrograph. The CCD accumulated the Raman signal for about 90-120 s before being read out to an interfaced PC computer with 10-30 of these scans added together to get the resonance Raman spectrum. The Raman shifts of the resonance Raman spectra were calibrated with the known vibrational frequencies of the cyclohexane solvent Raman bands and the solvent Raman bands were then subtracted from the resonance Raman spectra by utilizing an appropriately scaled solvent spectrum. Sections of the resonance Raman spectra were fit to a baseline plus a sum of Lorentzian bands to determine the integrated areas of the Raman bands of interest. The FT-IR and FT-Raman spectra of thiophene in the neat liquid phase were acquired so as to do a vibrational analysis that could be used to help make vibrational assignments for the resonance Raman spectra. Depolarization ratio 


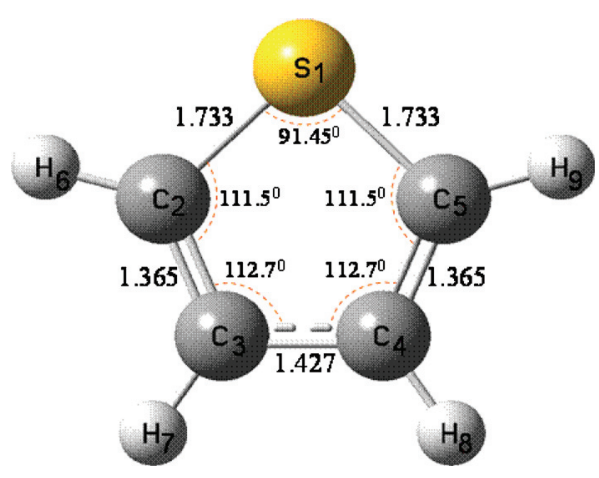

FIG. 1. A schematic of the optimized geometry structure of thiophene in its $\mathrm{S}_{0}$ state is shown. The selected bond lengths and bond angles indicated were calculated by using B3LYP/cc-PVTZ computations.

measurements were done with a Glan prism polarizer that was placed in the scattered beam just before the entrance slit of the spectrograph ${ }^{37}$ and the polarization response of the spectrometer was referenced to measurements of the cyclohexane bands that were employed as a standard. The three depolarized bands at 1347,1226 , and $1027 \mathrm{~cm}^{-1}$ gave $\rho$ values of $0.75 \pm 0.05$, while that for the $802 \mathrm{~cm}^{-1}$ band was $0.13 \pm 0.01$. These values suggest that the measured values (0.420 for $1394 \mathrm{~cm}^{-1}, 0.575$ for $1344 \mathrm{~cm}^{-1}, 0.502$ for $1074 \mathrm{~cm}^{-1}, 0.551$ for $1028 \mathrm{~cm}^{-1}, 0.777$ for $835 \mathrm{~cm}^{-1}$, and 1.006 for $754 \mathrm{~cm}^{-1}$ ) for thiophene are not affected by the polarization dependence of the grating efficiency nor by any appreciable leak of the polarization analyzer.

\section{B. Density functional theory and CASSCF computations}

DFT and CASSCF calculations ${ }^{38-40}$ were done to calculate the optimized geometry and vibrational frequencies as well as the electronic transition energies for the ground or excited electronic states of thiophene. Complete geometry optimization and vibrational frequency determination were accomplished with the B3LYP/cc-PVTZ level of theory for the ground state of thiophene and the $\operatorname{CASSCF}(8,7) / 6-31 \mathrm{G}^{*}$ level of theory for the excited states of thiophene, respectively. The electronic transition energies were computed with the B3LYP-TD/cc-PVTZ and $\operatorname{CASSCF}(8,7) / 6-31 G^{*}$ level of theory calculations. Seven active orbitals including one $\sigma_{\mathrm{C}-\mathrm{S}}$, two $\pi$, two $\pi^{*}$, one $\sigma_{\mathrm{C}-\mathrm{S}}{ }^{*}$, and one sulfur nonbonding orbital on the molecule were used for the CASSCF calculations which gives an active space with eight electrons in seven orbitals and is referred to as $\operatorname{CASSCF}(8,7)$ hereafter. All of the density functional theory and CASSCF calculations were performed with the GAUSSIAN program software suite. $^{41}$

\section{RESULTS AND DISCUSSION}

\section{A. The ground state geometry structure and vibrational assignments}

Figure 1 displays a schematic of the ground state geometry structure of thiophene obtained from the DFT calculations with the atoms numbered and the values of selected bond lengths and bond angles indicated in the structure. The vibrational spectra of thiophene and its isotopomers have been previously investigated by using IR spectroscopy ${ }^{42}$ and quantum mechanical computations. ${ }^{43,44}$ A normal coordinate analysis using empirical force fields has also been reported. ${ }^{45}$ Since there appears to be no previous literature reports of any Raman or resonance Raman spectra of thiophene, a FTRaman spectrum was measured and the vibrational frequencies of its Raman bands are shown in Table I. The ground state thiophene molecule belongs to the $\mathrm{C}_{2 \mathrm{~V}}$ molecular point group and has 21 vibrational modes that are partitioned into eight $A_{1}$, three $A_{2}$, three $B_{1}$, and seven $B_{2}$ irreducible representations, respectively, with all of the vibrational modes being Raman active and the modes with $\mathrm{A}_{1}, \mathrm{~B}_{1}$, and $\mathrm{B}_{2}$ being IR active. Table I gives the vibrational frequencies and their vibrational assignments and it appears that eight totally symmetric modes $\left(A_{1}\right)$ and one weak antisymmetric mode $\left(B_{2}\right)$ are observed in our FT-Raman spectrum.

\section{B. UV spectrum and the Resonance Raman spectra}

Figure 2 displays the room temperature UV spectra of thiophene in the gas phase and in cylohexane solution with the excitation wavelengths for the resonance Raman experiments indicated above the spectra. The structure, shape, and FMHW of the gas phase UV spectrum are very similar to those of the solution phase spectrum, although the $\lambda_{\max }$ $=228.6 \mathrm{~nm}$ for the gas phase UV spectrum is blueshifted about $3 \mathrm{~nm}$ relative to $\lambda_{\max }=231.6 \mathrm{~nm}$ for the solution phase spectrum, and this suggests that the solvent cage of cyclohexane solvent stabilizes the excited state molecule more than the ground state one. The absorption band was assigned as $\pi_{2} \rightarrow \pi_{4}{ }^{*}$ or $1{ }^{1} \mathrm{~A}_{1} \rightarrow 2{ }^{1} \mathrm{~A}_{1}$ transition. ${ }^{9,19,23}$ Therefore our 239.5 and $266 \mathrm{~nm}$ excitation wavelengths for the resonance Raman experiments are in resonance with this intense A-band absorption.

The 239.5 and $266 \mathrm{~nm}$ resonance Raman spectra were obtained for thiophene in cyclohexane solution and these spectra are shown in Fig. 3 along with a FT-Raman spectrum. The role of solvent in the structural dynamics of thiophene is not intent in this paper due to the difficulty in acquiring the gas phase resonance Raman spectra. However a weak van der Waals interaction between the nonpolar cyclohexane and weak polar thiophene in the excited state are expected to not alter the nature of the structural dynamics of thiophene. Thus in following subsections the spectra and the short-time dynamics are analyzed without considering the solvent effects. The FT-Raman spectrum in Fig. 3 displays seven fundamentals, among which $\nu_{3}, \nu_{4}, \nu_{5}, \nu_{6}, \nu_{7}$, and $\nu_{8}$ are of $\mathrm{A}_{1}$ symmetry and $\nu_{21}$ is of $\mathrm{B}_{2}$ symmetry (see also Table I). In contrast, the $239.5 \mathrm{~nm}$ resonance Raman spectrum in Fig. 3 displays three new bands at 906, 1134, and $1244 \mathrm{~cm}^{-1}$ in the $<1500 \mathrm{~cm}^{-1}$ frequency region that are not seen in the FT-Raman spectrum. The $266 \mathrm{~nm}$ spectrum in Fig. 3 displays preresonance features and is used to help ascertain what fundamentals appear in the $239.5 \mathrm{~nm}$ resonance Raman spectrum. Figure 4 presents an expanded view of the $239.5 \mathrm{~nm}$ resonance Raman spectrum with tentative vibrational assignments indicated above the spectrum and the solvent subtraction artifacts indicated by asterisks. The vibra- 
TABLE I. The B3LYP/cc-PVTZ computed and FT-IR, FT-Raman, and resonance Raman measured vibrational frequencies of thiophene are listed.

\begin{tabular}{|c|c|c|c|c|c|c|c|c|}
\hline \multirow{2}{*}{\multicolumn{2}{|c|}{ Sym. modes }} & \multicolumn{2}{|c|}{$\begin{array}{c}\text { Computed } \\
\left(\mathrm{cm}^{-1}\right)\end{array}$} & \multicolumn{4}{|c|}{ Experimental } & \multirow{2}{*}{$\begin{array}{l}\text { Assignment } \\
\text { Description }^{\mathrm{d}}\end{array}$} \\
\hline & & a & b & IR & Raman & $\mathrm{IR}^{\mathrm{c}}$ & $\mathrm{RR}$ & \\
\hline \multirow[t]{8}{*}{$\mathrm{A}_{1}$} & $\nu_{1}$ & 3248 & 3115 & 3106 & 3109 & 3126 & & $\mathrm{C}_{2} \mathrm{H}_{6} / \mathrm{C}_{5} \mathrm{H}_{9}$ in-plane sym. stretch \\
\hline & $\nu_{2}$ & 3209 & 3078 & 3071 & 3083 & 3098 & & $\mathrm{H}_{7} \mathrm{C}_{3}-\mathrm{C}_{4} \mathrm{H}_{8}$ in-plane sym. stretch \\
\hline & $\nu_{3}$ & 1447 & 1406 & 1408 & 1408 & 1409 & 1394 & $\mathrm{C}_{2}=\mathrm{C}_{3}-\mathrm{C}_{4}=\mathrm{C}_{5}$ in-plane sym. stretch \\
\hline & $\nu_{4}$ & 1395 & 1357 & & 1359 & 1360 & 1344 & $\mathrm{C}_{2}=\mathrm{C}_{3}-\mathrm{C}_{4}=\mathrm{C}_{5}$ in-plane sym. stretch \\
\hline & $\nu_{5}$ & 1106 & 1083 & 1082 & 1080 & 1083 & 1074 & $\mathrm{C}-\mathrm{H}$ in-plane wag \\
\hline & $\nu_{6}$ & 1052 & 1031 & 1034 & 1034 & 1036 & 1028 & $\mathrm{C}_{3}-\mathrm{C}_{4}$ stetch $+\mathrm{C}=\mathrm{C}-\mathrm{C}$ bend \\
\hline & $\nu_{7}$ & 834 & 824 & 834 & 833 & 839 & 835 & $\mathrm{C}-\mathrm{S}$ in-plane sym. stretch $+\mathrm{C}-\mathrm{C}=\mathrm{C}$ bend \\
\hline & $\nu_{8}$ & 614 & 616 & & 605 & 608 & 615 & $\mathrm{C}-\mathrm{S}-\mathrm{C}$ bend \\
\hline \multirow[t]{5}{*}{$\mathrm{A}_{2}$} & $\nu_{9}$ & 916 & 902 & & & 898 & 906 & $\mathrm{H}_{7} \mathrm{C}_{3}-\mathrm{C}_{4} \mathrm{H}_{8}$ twist \\
\hline & $\nu_{10}$ & 684 & 682 & & & 683 & & $\mathrm{C}_{2} \mathrm{H}_{6} / \mathrm{C}_{5} \mathrm{H}_{9}$ twist \\
\hline & $\nu_{11}$ & 572 & 576 & & & 565 & & $\mathrm{C}-\mathrm{C}=\mathrm{C}-\mathrm{C}$ out-of-plane deformation \\
\hline & & & & & & & 1134 & $2 \nu_{11}$ \\
\hline & & & & & & & 1244 & $\nu_{10}+\nu_{11}$ \\
\hline \multirow[t]{4}{*}{$\mathrm{B}_{1}$} & $\nu_{12}$ & 878 & 866 & & & 867 & & $\mathrm{CH}$ rock \\
\hline & $\nu_{13}$ & 720 & 716 & 712 & & 712 & & $\mathrm{CH}$ rock \\
\hline & $\nu_{14}$ & 454 & 464 & & 453 & 452 & & Ring out-of-plane deformation \\
\hline & $2 \nu_{14}$ & & & & & & 906 & \\
\hline \multirow[t]{7}{*}{$\mathrm{B}_{2}$} & $\nu_{15}$ & 3245 & 3113 & & & 3125 & & $\mathrm{C}_{2} \mathrm{H}_{6} / \mathrm{C}_{5} \mathrm{H}_{9}$ in-plane antisym. stretch \\
\hline & $\nu_{16}$ & 3196 & 3066 & 3071 & & 3098 & & $\mathrm{H}_{7} \mathrm{C}_{3}-\mathrm{C}_{4} \mathrm{H}_{8}$ in-plane antisym. stretch \\
\hline & $\nu_{17}$ & 1558 & & & & 1507 & & $\mathrm{C}_{2}=\mathrm{C}_{3}-\mathrm{C}_{4}=\mathrm{C}_{5}$ in-plane antisym. stretch \\
\hline & $\nu_{18}$ & 1276 & 1244 & 1252 & & 1256 & 1244 & $\mathrm{C}-\mathrm{H}$ in-plane wag \\
\hline & $\nu_{19}$ & 1108 & 1085 & & & 1085 & & $\mathrm{C}-\mathrm{H}$ in-plane wag \\
\hline & $\nu_{20}$ & 877 & 866 & 870 & & 872 & & $\mathrm{C}=\mathrm{C}-\mathrm{C}$ bend \\
\hline & $\nu_{21}$ & 745 & 740 & & 750 & 751 & 754 & $\mathrm{C}-\mathrm{S}$ in-plane antisym. stretch $+\mathrm{C}-\mathrm{C}=\mathrm{C}$ bend \\
\hline
\end{tabular}

tional assignments of Fig. 4 are based on those given in Table I for the correlations of the calculated DFT vibrational frequencies to the observed experimental vibrational frequencies. The intensity of some Raman bands in the spectrum could have contributions from several Raman bands that have similar Raman shifts due to the limited resolution of the solution phase spectra and therefore the Raman band labels in Fig. 4 only provide the largest Raman band contributions to each Raman feature.

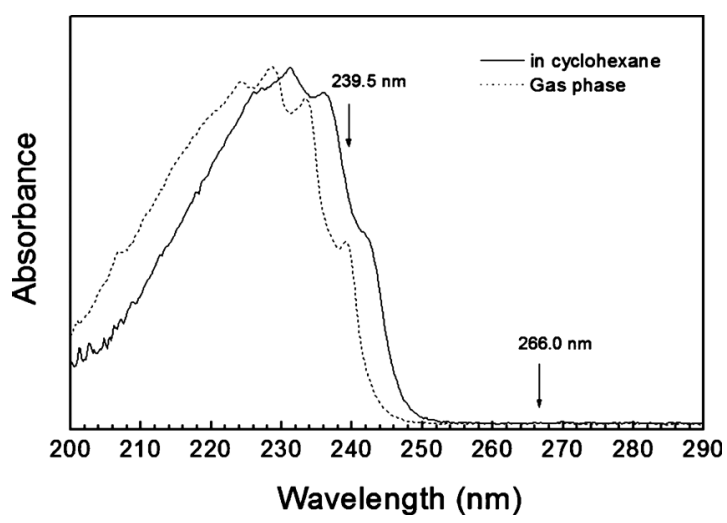

FIG. 2. The UV spectra of thiophene in the gas phase (dotted line) and in cylohexane solution (solid line) are displayed with the excitation wavelengths employed for the resonance Raman experiments indicated above the spectra.
A resonance Raman spectrum typically displays only the total symmetry vibrational modes if the excitation wavelength used to acquire the resonance Raman spectrum is resonant with a transition allowed single electronic transition. This has been the case in many molecular systems with relatively higher molecular symmetry point groups. For example, all of the Franck-Condon (FC) active vibrational modes displayed in the A-band resonance Raman spectra of nitrobenzene are of the $A_{1}$ irreducible representation since the A-band absorption is a single nondegenerate electronic state. ${ }^{35}$ However in some cases where vibronic-coupling occurs or the vibrational frequency along that vibrational mode changes between ground and excited electronic states (the standard A-term mechanism), a resonance Raman spectrum may display additional antisymmetric modes or the even overtones of the antisymmetric fundamental modes. ${ }^{33}$

Most of the resonance Raman features can be assigned to the fundamentals, overtones, and combination bands of about nine vibrational modes based on the information in Table I: the $\mathrm{C}_{2}=\mathrm{C}_{3}-\mathrm{C}_{4}=\mathrm{C}_{5}$ in-plane symmetric stretch modes $\nu_{3}\left(\mathrm{~A}_{1}\right)$ at $1394 \mathrm{~cm}^{-1}$ and $\nu_{4}\left(\mathrm{~A}_{1}\right)$ at $1344 \mathrm{~cm}^{-1}$, the $\mathrm{C}-\mathrm{H}$ in-plane wag mode $\nu_{18}\left(\mathrm{~B}_{2}\right)$ at $1244 \mathrm{~cm}^{-1}$, the $\mathrm{C}-\mathrm{H}$ in-plane wag mode $\nu_{5}\left(\mathrm{~A}_{1}\right)$ at $1074 \mathrm{~cm}^{-1}$, the $\mathrm{C}_{3}-\mathrm{C}_{4}$ stretch $+\mathrm{C}=\mathrm{C}-\mathrm{C}$ bend mode $\nu_{6}\left(\mathrm{~A}_{1}\right)$ at $1028 \mathrm{~cm}^{-1}$, the $\mathrm{C}-\mathrm{S}$ in-plane symmetric stretch $+\mathrm{C}-\mathrm{C}=\mathrm{C}$ bend mode $\nu_{7}\left(\mathrm{~A}_{1}\right)$ at $835 \mathrm{~cm}^{-1}$, the $\mathrm{C}-\mathrm{S}-\mathrm{C}$ bend mode $\nu_{8}\left(\mathrm{~A}_{1}\right)$ at $615 \mathrm{~cm}^{-1}$, 


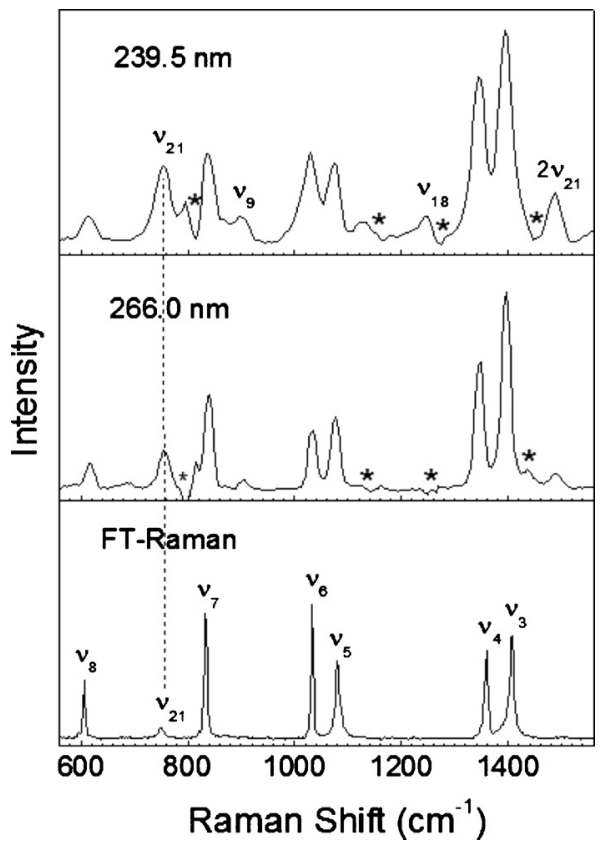

FIG. 3. A comparison of the FT-Raman spectrum with the 239.5 and $266 \mathrm{~nm}$ resonance Raman spectra is presented.

the $\mathrm{C}-\mathrm{S}$ antisymmetry stretch $+\mathrm{C}-\mathrm{C}=\mathrm{C}$ bend mode $\nu_{21}\left(\mathrm{~B}_{2}\right)$ at $754 \mathrm{~cm}^{-1}$, and the $\mathrm{H}_{7} \mathrm{C}_{3}-\mathrm{C}_{4} \mathrm{H}_{8}$ twist $\nu_{9}\left(\mathrm{~A}_{2}\right)$ at $906 \mathrm{~cm}^{-1}$. Alternatively 1244 and $906 \mathrm{~cm}^{-1}$ can, respectively, be assigned as $\nu_{10}\left(\mathrm{~A}_{2}\right)+\nu_{11}\left(\mathrm{~A}_{2}\right)$ and $2 \nu_{14}\left(\mathrm{~B}_{1} \times \mathrm{B}_{1}\right)$ in terms of the standard A-term mechanism. Detailed explanations of the vibrational assignments can be found in Sec. III E.

Figure 4 shows that the $\mathrm{C}-\mathrm{S}$ in-plane antisymmetric stretch $+\mathrm{C}-\mathrm{C}=\mathrm{C}$ bend mode $\nu_{21}$ at $754 \mathrm{~cm}^{-1}$ and the $\mathrm{C}_{2}=\mathrm{C}_{3}-\mathrm{C}_{4}=\mathrm{C}_{5}$ in-plane symmetric stretch $\nu_{4}$ at $1344 \mathrm{~cm}^{-1}$ have the most intense overtones progressions and form combination bands with other fundamentals. This indicates that the FC region structural dynamics of thiophene in the first intense absorption band are mostly along the inplane antisymmetric $\mathrm{C}-\mathrm{S}$ stretch and the in-plane symmetric $\mathrm{C}_{2}=\mathrm{C}_{3}-\mathrm{C}_{4}=\mathrm{C}_{5}$ stretch reaction coordinates. It is very interesting to note from Fig. 4 that the $\mathrm{C}-\mathrm{S}$ antisymmetric stretch $+\mathrm{C}-\mathrm{C}=\mathrm{C}$ bend mode $\nu_{21}\left(\mathrm{~B}_{2}\right)$ at $754 \mathrm{~cm}^{-1}$ possesses much more Raman intensity than the $\mathrm{C}-\mathrm{S}$ in-plane symmetric stretch $+\mathrm{C}-\mathrm{C}=\mathrm{C}$ bend mode $\nu_{7}\left(\mathrm{~A}_{1}\right)$ at $835 \mathrm{~cm}^{-1}$. This indicates that the thiophene molecule in the $2{ }^{1} \mathrm{~A}_{1}$ state undergoes large bond length changes along the two $\mathrm{C}-\mathrm{S}$ bond lengths with one $\mathrm{C}-\mathrm{S}$ bond becoming much longer while the other becomes somewhat shorter. This kind of short-time dynamics suggests that a ring opening reaction may occur in or nearby the $\mathrm{FC}$ region due to a curve-crossing between $2{ }^{1} \mathrm{~A}_{1}$ and an upper excited state that has a $\mathrm{B}_{2}$ irreducible representation. In addition the $\mathrm{H}_{7} \mathrm{C}_{3}-\mathrm{C}_{4} \mathrm{H}_{8}$ twist $\nu_{9}\left(\mathrm{~A}_{2}\right)$ displays moderate resonance Raman intensity and forms combination bands with $\nu_{4}$ at $1344 \mathrm{~cm}^{-1}$, etc., but does not form combination bands with $\nu_{21}\left(\mathrm{~B}_{2}\right)$ at $754 \mathrm{~cm}^{-1}$. This suggests that the curve-crossing between $2{ }^{1} \mathrm{~A}_{1}$ and an upper excited state that has $\mathrm{A}_{2}$ irreducible representation may also exist in the $\mathrm{FC}$ region for thiophene.

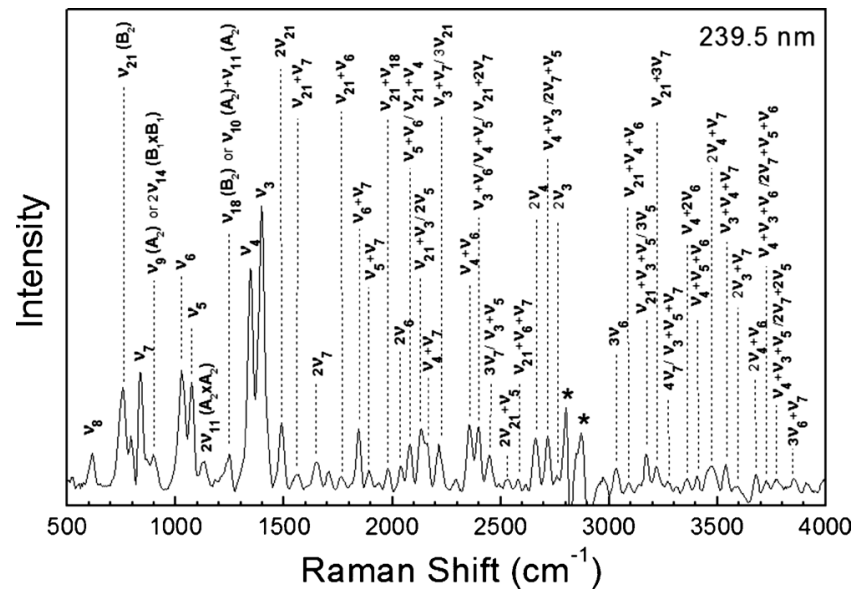

FIG. 4. An expanded view of the $239.5 \mathrm{~nm}$ resonance Raman spectrum of thiophene in cylochexane solution is shown. The vibrational assignments made use of Table I. The spectrum has been solvent subtracted.

We have noted that depolarization ratios of the Raman bands observed in the resonance Raman spectrum provide us a useful criterion for vibronic-coupling between two or more excited states. In general, if two nondegenerate electronic transitions lie close together, the depolarization ratio value will depend on the ratio $\alpha_{\mathrm{xx}} / \alpha_{\mathrm{yy}}$, where $\alpha_{\mathrm{xx}}$ and $\alpha_{\mathrm{yy}}$ are, respectively, the diagonal components of transition polarizability. ${ }^{46}$ The common cases of $\rho=1 / 3$ and $1 / 8 \leq \rho$ $\leq 1 / 3$ are, respectively, observed for a single nondegenerate excited state and an excited state having relatively weak vibronic-coupling. ${ }^{47}$ However, these conventional values have to be altered if the $\alpha_{\mathrm{xx}} / \alpha_{\mathrm{yy}}$ value becomes negative, ${ }^{46}$ or the curve-crossing between two state surfaces occurs. ${ }^{48-50}$ As an example, the appearance of nontotally symmetry mode of the ethylenic hydrogen out-of-plane wag $\left(\mathrm{A}_{\mathrm{u}}\right)$ at $956 \mathrm{~cm}^{-1}$ in the A-band resonance Raman spectra of stilbene was previously ascribed to the existence of the vibroniccoupling of the $S_{1}$ state to nearby states for trans-stilbene ${ }^{48}$ and this was also supported by the recent CASSCF and CASPT2 computations. ${ }^{49}$ Therefore that the vibrational modes $\nu_{3}, \nu_{4}, \nu_{5}, \nu_{6}$, and $\nu_{7}$ of thiophene have the measured depolarization ratio values ranged from 0.42 to 0.75 , which could be an indication that two or more states contributing to the $239.7 \mathrm{~nm}$ resonance Raman spectra. In other words, the curve-crossing or vibronic-coupling between $2{ }^{1} \mathrm{~A}_{1}$ and $1{ }^{1} \mathrm{~B}_{2}$ or $1{ }^{1} \mathrm{~B}_{1}$ states likely exists in the Franck-Condon region.

\section{Electronic transitions, excited state structures and conical intersections}

In order to explore the $\mathrm{FC}$ region curve-crossing points and the reaction dynamics of thiophene, we carried out CASSCF calculations to determine the vertical transition energies and the optimized excited state geometries as well as the geometry structures of the conical intersections. Table II lists the $\operatorname{CASSCF}(8,7) / 6-31 \mathrm{G}^{*}$ calculated minimal singlet and triplet excitation energies $\Delta \mathrm{E}$ of the $2{ }^{1} \mathrm{~A}_{1}, 1{ }^{1} \mathrm{~B}_{2}, 1{ }^{1} \mathrm{~B}_{1}$, and $1{ }^{3} \mathrm{~B}_{2}, 1{ }^{3} \mathrm{~A}_{1}$ and $1{ }^{3} \mathrm{~B}_{1}$ states and minimal energies $\Delta \mathrm{E}(\mathrm{CI})$ of the conical intersection points ${ }^{1} \mathrm{~B}_{1} /{ }^{1} \mathrm{~A}_{1}$ and ${ }^{1} \mathrm{~B}_{2} /{ }^{1} \mathrm{~A}_{1}$, as well as vertical transition energies $\Delta \mathrm{E}(\mathrm{FC})$ of 
TABLE II. CASSCF $(8,7) / 6-31 \mathrm{G}^{*}$ computed minimal singlet and triplet excitation energies $\Delta \mathrm{E}$ of the $2{ }^{1} \mathrm{~A}_{1}, 1{ }^{1} \mathrm{~B}_{2}, 1{ }^{1} \mathrm{~B}_{1}, 1{ }^{3} \mathrm{~B}_{2}, 1{ }^{3} \mathrm{~A}_{1}$, and $1{ }^{3} \mathrm{~B}_{1}$ excited states and minimal energies $\Delta \mathrm{E}(\mathrm{CI})$ of the conical intersections points ${ }^{1} \mathrm{~B}_{1} /{ }^{1} \mathrm{~A}_{1}$ and ${ }^{1} \mathrm{~B}_{2} /{ }^{1} \mathrm{~A}_{1}$, and vertical transition energies $\Delta \mathrm{E}(\mathrm{FC})$ of the $2{ }^{1} \mathrm{~A}_{1}$ and $1{ }^{1} \mathrm{~B}_{2}$ state for thiophene. $\pi_{2}, \pi_{3}$, and $\pi_{4}{ }^{*}$ are, respectively, $\pi_{\mathrm{HOMO}-1}, \pi_{\mathrm{HOMO}}$, and $\pi_{\text {LUMO }}{ }^{*}$ orbitals. FC is an abbreviation of the FranckCondon region. $1{ }^{1} \mathrm{~A}_{1}$ is the electronic ground state.

\begin{tabular}{lcc}
\hline \hline State & Electronic structure & $\begin{array}{c}\Delta \mathrm{E} \\
{[\mathrm{kcal} / \mathrm{mol}(\mathrm{eV})]}\end{array}$ \\
\hline $1{ }^{1} \mathrm{~A}_{1}$ & 0.0 \\
$2{ }^{1} \mathrm{~A}_{1}$ & $\pi_{2} \rightarrow \pi_{4}{ }^{*}$ & $130.78(5.671)$ \\
$1{ }^{1} \mathrm{~B}_{2}$ & $\pi_{3} \rightarrow \pi_{4}{ }^{*}$ & $130.83(5.673)$ \\
$1{ }^{1} \mathrm{~B}_{1}$ & $\pi_{3} \rightarrow \sigma_{\mathrm{C}-{ }^{*}}$ & $84.1(3.65)$ \\
$1{ }^{3} \mathrm{~B}_{2}$ & $\pi_{3} \rightarrow \pi_{4}{ }^{*}$ & $71.8(3.11)$ \\
$1{ }^{3} \mathrm{~A}_{1}$ & $\pi_{2} \rightarrow \pi_{4}{ }^{*}$ & $111.9(4.85)$ \\
$1{ }^{3} \mathrm{~B}_{1}$ & $\pi_{3} \rightarrow \sigma_{\mathrm{C}-\mathrm{S}^{*}}$ & $76.7(3.32)$ \\
& & $\Delta \mathrm{E}(\mathrm{CI})$ \\
${ }^{1} \mathrm{~B}_{1} /{ }^{1} \mathrm{~A}_{1}$ & & $144.9(6.28)$ \\
${ }^{1} \mathrm{~B}_{2} /{ }^{1} \mathrm{~A}_{1}$ & & $142.8(6.19)$ \\
& & $\Delta \mathrm{E}(\mathrm{FC})$ \\
$2{ }^{1} \mathrm{~A}_{1}$ & $\pi_{2} \rightarrow \pi_{4}{ }^{*}$ & $145.3(6.30)$ \\
$1{ }^{1} \mathrm{~B}_{2}$ & $\pi_{3} \rightarrow \pi_{4}{ }^{*}$ & $174.2(7.55)$ \\
\hline \hline
\end{tabular}

$2{ }^{1} \mathrm{~A}_{1}$ and $1{ }^{1} \mathrm{~B}_{2}$ for thiophene. The corresponding optimized geometry structural parameters are listed in Table III. Figure 5 presents the $\operatorname{CASSCF}(8,7) / 6-31 \mathrm{G}^{*}$ computed optimized geometry structures of thiophene in $2{ }^{1} \mathrm{~A}_{1}, 1{ }^{1} \mathrm{~B}_{2}, 1{ }^{1} \mathrm{~B}_{1}$, and $1{ }^{3} \mathrm{~B}_{2}, 1{ }^{3} \mathrm{~A}_{1}$ and $1{ }^{3} \mathrm{~B}_{1}$ excited states, and in conical intersection points ${ }^{1} \mathrm{~B}_{1} /{ }^{1} \mathrm{~A}_{1}$ and ${ }^{1} \mathrm{~B}_{2} /{ }^{1} \mathrm{~A}_{1}$. Figure 5 and Table III show that the molecular symmetry of the $\operatorname{CASSCF}(8,7) / 6-31 \mathrm{G}^{*}$ optimized geometry structures of the $2{ }^{1} \mathrm{~A}_{1}, 1{ }^{1} \mathrm{~B}_{2}, 1{ }^{3} \mathrm{~B}_{2}$, and $1{ }^{3} \mathrm{~A}_{1}$ excited states are all in the $\mathrm{C}_{1}$ point group. The $\mathrm{C}-\mathrm{S}$ and $\mathrm{C}-\mathrm{C}$ bonds of the $2{ }^{1} \mathrm{~A}_{1}$ geometry are all elongated relative to the electronic ground state. The largest bond length changes occur to the $\mathrm{C}_{2}-\mathrm{C}_{3} / \mathrm{C}_{4}-\mathrm{C}_{5}$ bonds $(\sim 1.474 \AA)$ which are longer than the ground state ones by $\sim 0.11 \AA$. The explanation for this is that the $\pi_{2} \rightarrow \pi_{4}^{*}$ transition weakens the $\mathrm{C}_{2}-\mathrm{C}_{3} / \mathrm{C}_{4}-\mathrm{C}_{5}$ bonds. The optimized geometry structure of the $1^{3} \mathrm{~A}_{1}$ state is in general very similar to that of the $2{ }^{1} \mathrm{~A}_{1}$ state except for the $\mathrm{S}_{1}-\mathrm{C}_{2} / \mathrm{S}_{1}-\mathrm{C}_{5}$ and $\mathrm{C}_{3}-\mathrm{C}_{4}$ bond lengths that become, respectively, a bit longer and much shorter. The molecular orbital and electronic density population analysis indicates that such geometry parameter changes between the $2{ }^{1} \mathrm{~A}_{1}$ and $1{ }^{3} \mathrm{~A}_{1}$ states are likely due to the pyramidilization or a biradical character of the $\mathrm{C}_{2}$ and $\mathrm{C}_{5}$ atoms of thiophene in the $1{ }^{3} \mathrm{~A}_{1}$ state. Similarly, the $1{ }^{1} \mathrm{~B}_{2}$ and $1{ }^{3} \mathrm{~B}_{2}$ geometry structures are basically similar to the $2{ }^{1} \mathrm{~A}_{1}$ and $1{ }^{3} \mathrm{~A}_{1}$ ones, respectively. The major structural differences between those of the $2{ }^{1} \mathrm{~A}_{1}$ and $1{ }^{1} \mathrm{~B}_{2}$ states are the orientations of the $\mathrm{S}$ atom and the four $\mathrm{H}$ atoms. The $2{ }^{1} \mathrm{~A}_{1}$ geometry structure shows a significant out-of-plane motion with $\mathrm{S}, \mathrm{H}_{6}$, and $\mathrm{H}_{9}$ atoms moving simultaneously upward, while the $1{ }^{1} \mathrm{~B}_{2}$ geometry structure displays a significant out-of-plane motion too but with $\mathrm{H}_{6} / \mathrm{H}_{7}$ atoms and $\mathrm{S} / \mathrm{H}_{8} / \mathrm{H}_{9}$ atoms bending, respectively, downward and upward from the molecular plane. The $\operatorname{CASSCF}(8,7) / 6-31 \mathrm{G}^{*}$ computed optimized geometry structures of thiophene in the $1{ }^{1} \mathrm{~B}_{1}$ and $1{ }^{3} \mathrm{~B}_{1}$ states are planar. Their most prominent features are that the two $\mathrm{C}-\mathrm{S}$ bonds undergo opposite bond length changes relative to the ground state ones with one $\mathrm{C}-\mathrm{S}$ bond becoming much longer $\left(3.258 \AA\right.$ for $1{ }^{1} \mathrm{~B}_{1}$ and $3.221 \AA$ for $\left.1{ }^{3} \mathrm{~B}_{1}\right)$ and the other $\mathrm{C}-\mathrm{S}$ bond becoming shorter $\left(1.725 \AA\right.$ for $1{ }^{1} \mathrm{~B}_{1}$ and $1.675 \AA$ for $\left.1{ }^{3} \mathrm{~B}_{1}\right)$. This indicates that the $1{ }^{1} \mathrm{~B}_{1}$ and $1{ }^{3} \mathrm{~B}_{1}$ states are likely dissociative. Molecular orbital and electronic density analysis reveal that thiophene in the $1{ }^{3} \mathrm{~B}_{1}$ state has a biradical character with the electronic density centered on the sulfur atom and the $\mathrm{C}_{5}$ atom.

We note that the optimized geometry structures of thiophene in the $2{ }^{1} \mathrm{~A}_{1}, 1{ }^{1} \mathrm{~B}_{2}, 1{ }^{1} \mathrm{~B}_{1}, 1{ }^{3} \mathrm{~B}_{2}, 1{ }^{3} \mathrm{~A}_{1}$, and $1{ }^{3} \mathrm{~B}_{1}$ states and the corresponding adiabatic transition energies were studied by using the DFT/MRCI level of theory calculations. ${ }^{23}$ In general our $\operatorname{CASSCF}(8,7) / 6-31 \mathrm{G}^{*}$ computed geometry structures agree qualitatively with those obtained by DFT/MRCI methods. For example, both methods predict that the $1{ }^{1} \mathrm{~B}_{1}$ state is dissociative along one $\mathrm{C}-\mathrm{S}$ bond and is a global minimum on the first singlet potential energy hypersurface, while the $2{ }^{1} \mathrm{~A}_{1}, 1{ }^{1} \mathrm{~B}_{2}$ and $1{ }^{3} \mathrm{~B}_{2}, 1{ }^{3} \mathrm{~A}_{1}$ states are bound although the degrees of the bond length and bond angle changes are somewhat different. DFT/MRCI predicted an out-of-plane structure for the $1{ }^{1} \mathrm{~B}_{2}$ state with the $\mathrm{S}$ atom and the $\mathrm{H}_{6} / \mathrm{H}_{9}$ atoms being downward and upward from the molecular plane, ${ }^{23}$ this is different from the $\operatorname{CASSCF}(8,7) / 6-31 \mathrm{G}^{*}$ structure that shows an out-of-plane geometry for the $1{ }^{1} \mathrm{~B}_{2}$ state with the $\mathrm{H}_{6} / \mathrm{H}_{7}$ atoms and the $\mathrm{S} / \mathrm{H}_{8} / \mathrm{H}_{9}$ atoms being downward and upward, respectively. The energetic order of the minimal electronic transition energies follow similar trends of $1{ }^{1} \mathrm{~B}_{1}<2{ }^{1} \mathrm{~A}_{1}<1{ }^{1} \mathrm{~B}_{2}$, although the values are noticeably different for the two methods. The minimal electronic transition energies of the $1{ }^{1} \mathrm{~B}_{1}$ and $2{ }^{1} \mathrm{~A}_{1}$ state predicted by previous DFT/MRCI are 5.54 or $5.39 \mathrm{eV}$, respectively, which are somewhat smaller than the corresponding 5.673 and $5.671 \mathrm{eV}$ predicted by our CASSCF $/ 6-31 \mathrm{G}^{*}$ computations. The most important difference, however, lies in the loss of the molecular symmetry predicted by $\operatorname{CASSCF}(8,7) / 6-31 \mathrm{G}^{*}$ optimization for the structures of the $2{ }^{1} \mathrm{~A}_{1}, 1{ }^{1} \mathrm{~B}_{2}, 1{ }^{3} \mathrm{~B}_{2}$, and $1{ }^{3} \mathrm{~A}_{1}$ states. The very strong electronic interactions (or state mixings) among the $2{ }^{1} \mathrm{~A}_{1}$ and $1{ }^{1} \mathrm{~B}_{2}$ bound states and the $1{ }^{1} \mathrm{~B}_{1}$ dissociative state or among the $1{ }^{3} \mathrm{~A}_{1}$ and $1{ }^{3} \mathrm{~B}_{2}$ bound states and the $1{ }^{3} \mathrm{~B}_{1}$ dissociative state are likely the origins for this loss of symmetry. For example, the $\operatorname{CASSCF}(8,7) / 6-31 \mathrm{G}^{*}$ and the DFT/MRCI (Ref. 23) as well as the linear vibronic-coupling ${ }^{32}$ studies demonstrate consistently that the minimal transition energies of the $2{ }^{1} \mathrm{~A}_{1}$ and $1{ }^{1} \mathrm{~B}_{2}$ states and the corresponding conical intersections ${ }^{1} \mathrm{~B}_{1} /{ }^{1} \mathrm{~A}_{1},{ }^{1} \mathrm{~B}_{2} /{ }^{1} \mathrm{~A}_{1}$, and ${ }^{1} \mathrm{~B}_{1} /{ }^{1} \mathrm{~B}_{2}$ are close in energy. This breaks the $\mathrm{A}_{1}$ symmetry for the $2{ }^{1} \mathrm{~A}_{1}$ state after the wave-packet goes away from the $\mathrm{FC}$ region.

To map out the possible conical intersections between the $2{ }^{1} \mathrm{~A}_{1}$ potential energy surface and other surfaces that may result in a lower $\mathrm{C}_{1}$ or Cs dynamical symmetry for the $2{ }^{1} \mathrm{~A}_{1}$ state structural dynamics of thiophene, we carried out state-averaged-CASSCF (SA-CASSCF) (Ref. 51) calculations with $6-31 \mathrm{G}^{*}$ basis sets. Inspection of the SA-CASSCF calculated active orbitals and their one-electron densities for thiophene in Table IV reveals that the optimized crossing point denoted as ${ }^{1} \mathrm{~B}_{1} /{ }^{1} \mathrm{~A}_{1}$ corresponds to one between the 
TABLE III. CASSCF $(8,7) / 6-31 \mathrm{G}^{*}$ computed optimized geometry structural parameters of the $2{ }^{1} \mathrm{~A}_{1}, 1{ }^{1} \mathrm{~B}_{2}, 1{ }^{1} \mathrm{~B}_{1}, 1{ }^{3} \mathrm{~B}_{2}, 1{ }^{3} \mathrm{~A}_{1}$, and $1{ }^{3} \mathrm{~B}_{1}$ excited states and the conical intersection points ${ }^{1} \mathrm{~B}_{1} /{ }^{1} \mathrm{~A}_{1}$ and ${ }^{1} \mathrm{~B}_{2} /{ }^{1} \mathrm{~A}_{1}$ of thiophene.

\begin{tabular}{|c|c|c|c|c|c|c|c|c|c|}
\hline Parameters & $\mathrm{S}_{0}$ & $2{ }^{1} \mathrm{~A}_{1}$ & $1{ }^{1} \mathrm{~B}_{2}$ & $1{ }^{1} \mathrm{~B}_{1}$ & $1{ }^{3} \mathrm{~B}_{2}$ & $1{ }^{3} \mathrm{~A}_{1}$ & $1{ }^{3} \mathrm{~B}_{1}$ & ${ }^{1} \mathrm{~B}_{1} /{ }^{1} \mathrm{~A}_{1}$ & ${ }^{1} \mathrm{~B}_{2} /{ }^{1} \mathrm{~A}_{1}$ \\
\hline $\mathrm{R}_{\mathrm{S} 1-\mathrm{C} 2}$ & 1.733 & 1.795 & 1.795 & 3.258 & 1.807 & 1.790 & 3.221 & 1.997 & 1.921 \\
\hline $\mathrm{R}_{\mathrm{C} 2-\mathrm{C} 3}$ & 1.365 & 1.472 & 1.473 & 1.332 & 1.459 & 1.424 & 1.352 & 1.421 & 1.465 \\
\hline $\mathrm{R}_{\mathrm{C} 3-\mathrm{C} 4}$ & 1.427 & 1.451 & 1.451 & 1.476 & 1.352 & 1.505 & 1.435 & 1.432 & 1.412 \\
\hline $\mathrm{R}_{\mathrm{C} 4-\mathrm{C} 5}$ & 1.365 & 1.476 & 1.475 & 1.363 & 1.480 & 1.427 & 1.402 & 1.443 & 1.470 \\
\hline $\mathrm{R}_{\mathrm{S} 1-\mathrm{C} 5}$ & 1.733 & 1.752 & 1.753 & 1.725 & 1.782 & 1.761 & 1.675 & 1.695 & 1.713 \\
\hline $\mathrm{R}_{\mathrm{C} 2-\mathrm{H} 6}$ & 1.079 & 1.073 & 1.073 & 1.072 & 1.072 & 1.070 & 1.073 & 1.066 & 1.080 \\
\hline $\mathrm{R}_{\mathrm{C} 3-\mathrm{H} 7}$ & 1.082 & 1.071 & 1.072 & 1.080 & 1.073 & 1.073 & 1.080 & 1.072 & 1.073 \\
\hline $\mathrm{R}_{\mathrm{C} 4-\mathrm{H} 8}$ & 1.082 & 1.071 & 1.071 & 1.077 & 1.073 & 1.073 & 1.077 & 1.073 & 1.072 \\
\hline $\mathrm{R}_{\mathrm{C} 5-\mathrm{H} 9}$ & 1.079 & 1.074 & 1.074 & 1.075 & 1.075 & 1.070 & 1.077 & 1.070 & 1.073 \\
\hline$\angle_{\mathrm{C} 5-\mathrm{S} 1-\mathrm{C} 2}$ & 91.4 & 94.3 & 94.9 & 72.0 & 90.6 & 91.6 & 72.4 & 90.4 & 92.7 \\
\hline$\angle_{\mathrm{S} 1-\mathrm{C} 2-\mathrm{C} 3}$ & 111.5 & 108.2 & 108.7 & 82.8 & 110.5 & 112.5 & 83.0 & 106.5 & 104.5 \\
\hline$\angle_{\mathrm{C} 2}-\mathrm{C} 3-\mathrm{C} 4$ & 112.7 & 112.6 & 112.8 & 128.1 & 114.3 & 111.2 & 127.7 & 113.7 & 116.3 \\
\hline$\angle_{\mathrm{C} 3-\mathrm{C} 4-\mathrm{C} 5}$ & 112.7 & 113.3 & 113.4 & 130.3 & 113.9 & 111.6 & 129.3 & 115.6 & 112.9 \\
\hline$\angle_{\mathrm{C} 4-\mathrm{C} 5-\mathrm{S} 1}$ & 111.5 & 109.2 & 109.6 & 126.8 & 110.5 & 113.0 & 127.5 & 113.8 & 112.0 \\
\hline$\angle_{\mathrm{S} 1-\mathrm{C} 2-\mathrm{H} 6}$ & 119.9 & 117.1 & 117.6 & 145.7 & 119.9 & 119.8 & 147.3 & 119.6 & 112.3 \\
\hline$\angle_{\mathrm{C} 3-\mathrm{C} 2-\mathrm{H} 6}$ & 128.6 & 123.5 & 123.5 & 131.5 & 124.4 & 126.6 & 129.7 & 133.7 & 119.0 \\
\hline$\angle_{\mathrm{C} 2-\mathrm{C} 3-\mathrm{H} 7}$ & 123.3 & 122.6 & 122.4 & 117.4 & 121.3 & 122.1 & 117.0 & 123.2 & 120.7 \\
\hline$\angle_{\mathrm{C} 4-\mathrm{C} 3-\mathrm{H} 7}$ & 124.0 & 123.4 & 123.1 & 114.5 & 124.4 & 122.2 & 115.3 & 122.9 & 123.0 \\
\hline$\angle_{\mathrm{C} 3-\mathrm{C} 4-\mathrm{H} 8}$ & 124.0 & 124.0 & 124.0 & 114.3 & 124.9 & 122.8 & 115.4 & 123.3 & 124.7 \\
\hline$\angle_{\mathrm{C} 5-\mathrm{C} 4-\mathrm{H} 8}$ & 123.3 & 122.6 & 122.4 & 115.5 & 121.2 & 122.4 & 115.3 & 121.1 & 122.3 \\
\hline$\angle_{\mathrm{S} 1-\mathrm{C} 5-\mathrm{H} 9}$ & 119.9 & 117.4 & 118.2 & 116.2 & 118.0 & 119.5 & 117.1 & 120.9 & 121.3 \\
\hline$\angle_{\mathrm{C} 4-\mathrm{C} 5-\mathrm{H} 9}$ & 128.6 & 122.7 & 123.1 & 117.0 & 121.7 & 125.8 & 115.4 & 125.2 & 124.6 \\
\hline $\mathrm{D}_{\mathrm{S} 1-\mathrm{C} 2-\mathrm{C} 3-\mathrm{C} 4}$ & 0.0 & -12.0 & 8.5 & 0.0 & 2.3 & 2.8 & 0.0 & 0.0 & -4.9 \\
\hline $\mathrm{D}_{\mathrm{S} 1-\mathrm{C} 5-\mathrm{C} 4-\mathrm{C} 3}$ & 0.0 & 8.4 & 2.6 & 0.0 & -4.1 & 3.1 & 0.0 & 0.0 & 11.1 \\
\hline $\mathrm{D}_{\mathrm{C} 2-\mathrm{C} 3-\mathrm{C} 4-\mathrm{C} 5}$ & 0.0 & 2.6 & -7.4 & 0.0 & 1.1 & -3.8 & 0.0 & 0.0 & -3.3 \\
\hline $\mathrm{D}_{\mathrm{C} 5-\mathrm{S} 1-\mathrm{C} 2-\mathrm{C} 3}$ & 0.0 & 14.6 & -6.0 & 0.0 & -3.9 & -1.0 & 0.0 & 0.0 & 9.4 \\
\hline $\mathrm{D}_{\mathrm{C} 2-\mathrm{S} 1-\mathrm{C} 5-\mathrm{C} 4}$ & 0.0 & -13.2 & 2.1 & 0.0 & 4.4 & -1.0 & 0.0 & 0.0 & -11.7 \\
\hline $\mathrm{D}_{\mathrm{H} 6-\mathrm{C} 2-\mathrm{S} 1-\mathrm{C} 5}$ & 180.0 & 159.9 & -152.5 & 180.0 & 151.6 & -169.3 & 180.0 & 180.0 & -120.9 \\
\hline $\mathrm{D}_{\mathrm{H} 6-\mathrm{C} 2-\mathrm{C} 3-\mathrm{C} 4}$ & 180.0 & -154.6 & 152.6 & 180.0 & -151.8 & 170.3 & 180.0 & 180.0 & 121.3 \\
\hline $\mathrm{D}_{\mathrm{H} 7-\mathrm{C} 3-\mathrm{C} 2-\mathrm{S} 1}$ & 180.0 & -179.0 & -156.5 & 180.0 & -177.3 & -154.0 & 180.0 & 180.0 & 174.4 \\
\hline $\mathrm{D}_{\mathrm{H} 7-\mathrm{C} 3-\mathrm{C} 4-\mathrm{C} 5}$ & 180.0 & 169.4 & 157.6 & 180.0 & -179.3 & 153.0 & 180.0 & 180.0 & 177.4 \\
\hline $\mathrm{D}_{\mathrm{H} 7-\mathrm{C} 3-\mathrm{C} 2-\mathrm{H} 6}$ & 0.0 & 38.5 & -12.5 & 0.0 & 28.6 & 13.4 & 0.0 & 0.0 & -59.4 \\
\hline $\mathrm{D}_{\mathrm{H} 7-\mathrm{C} 3-\mathrm{C} 4-\mathrm{H} 8}$ & 0.0 & -6.6 & -18.1 & 0.0 & 0.4 & -46.9 & 0.0 & 0.0 & -5.7 \\
\hline $\mathrm{D}_{\mathrm{H} 8-\mathrm{C} 4-\mathrm{C} 5-\mathrm{H} 9}$ & 0.0 & -32.1 & -35.2 & 0.0 & -38.8 & 8.0 & 0.0 & 0.0 & 30.2 \\
\hline $\mathrm{D}_{\mathrm{H} 8-\mathrm{C} 4-\mathrm{C} 3-\mathrm{C} 2}$ & 180.0 & -173.5 & 176.9 & 180.0 & -179.1 & 156.3 & 180.0 & 180.0 & 173.6 \\
\hline $\mathrm{D}_{\mathrm{H} 8-\mathrm{C} 4-\mathrm{C} 5-\mathrm{S} 1}$ & 180.0 & -175.5 & 178.4 & 180.0 & 176.1 & -157.1 & 180.0 & 180.0 & -165.9 \\
\hline $\mathrm{D}_{\mathrm{H} 9-\mathrm{C} 5-\mathrm{C} 4-\mathrm{C} 3}$ & 180.0 & 151.8 & 149.0 & 180.0 & 141.0 & 168.2 & 180.0 & 180.0 & -152.9 \\
\hline $\mathrm{D}_{\mathrm{H} 9-\mathrm{C} 5-\mathrm{S} 1-\mathrm{C} 2}$ & 180.0 & -158.8 & -146.2 & 180.0 & -142.1 & -167.4 & 180.0 & 180.0 & 152.8 \\
\hline
\end{tabular}

$1{ }^{1} \mathrm{~B}_{1}$ and $2{ }^{1} \mathrm{~A}_{1}$ potential energy surfaces. The ${ }^{1} \mathrm{~B}_{1} /{ }^{1} \mathrm{~A}_{1}$ structure in Fig. 5 provides us the structural changes connecting the $\mathrm{FC}$ region of the $2{ }^{1} \mathrm{~A}_{1}$ state to the conical intersection point ${ }^{1} \mathrm{~B}_{1} /{ }^{1} \mathrm{~A}_{1}$ so that $\mathrm{R}_{\mathrm{S} 1-\mathrm{C} 2}$ and $\mathrm{R}_{\mathrm{S} 1-\mathrm{C} 5}$ for $\mathrm{CI}\left(\mathrm{S}_{3} / \mathrm{S}_{1}\right)$ are, respectively, $0.27 \AA$ longer and $0.03 \AA$ shorter relative to the corresponding ground state values. It is very interesting to note that minimal energies $\Delta \mathrm{E}(\mathrm{CI})$ for the conical intersection point ${ }^{1} \mathrm{~B}_{1} /{ }^{1} \mathrm{~A}_{1}$ is $6.28 \mathrm{eV}$ (with respect to $\mathrm{S}_{0}$ ), which is just slightly lower in energy than the vertical transition energy $[\Delta \mathrm{E}(\mathrm{FC})] 6.30 \mathrm{eV}$ for the $2{ }^{1} \mathrm{~A}_{1}$ state by about $0.4 \mathrm{kcal} / \mathrm{mol}$. This indicates that the conical intersection point ${ }^{1} \mathrm{~B}_{1} /{ }^{1} \mathrm{~A}_{1}$ is likely in the $\mathrm{FC}$ region of the $2{ }^{1} \mathrm{~A}_{1}$ state and is easily energy accessible. On the other hand, the calculated vertical transition energy $\Delta \mathrm{E}(\mathrm{FC})$ of the $2{ }^{1} \mathrm{~A}_{1}$ or $1{ }^{1} \mathrm{~B}_{2}$ states is 6.30 or $7.55 \mathrm{eV}$, respectively, while the minimal energy $\Delta \mathrm{E}(\mathrm{CI})$ of the conical intersection point ${ }^{1} \mathrm{~B}_{2} /{ }^{1} \mathrm{~A}_{1}$ is $6.19 \mathrm{eV}$, which is lower than the vertical transition energy $6.30 \mathrm{eV}$ of the $2{ }^{1} \mathrm{~A}_{1}$ state by about $2.5 \mathrm{kcal} / \mathrm{mol}$, suggesting that the conical intersection point ${ }^{1} \mathrm{~B}_{2} /{ }^{1} \mathrm{~A}_{1}$ is located in energy below the conical intersection point ${ }^{1} \mathrm{~B}_{1} /{ }^{1} \mathrm{~A}_{1}$ and is likely not very far away from the $\mathrm{FC}$ region.

\section{Excited state structural dynamics deduced from the resonance Raman spectra and CASSCF calculations}

The optimized geometry structure of thiophene in the $2{ }^{1} \mathrm{~A}_{1}$ state displays large changes along the $\mathrm{C}-\mathrm{S}$ and $\mathrm{C}-\mathrm{C}$ bond lengths and the out-of-plane deformation of the $\mathrm{S}$ atom, and the $\mathrm{H}_{6} / \mathrm{H}_{9}$ atoms, with the $\mathrm{C}_{2}-\mathrm{S}_{1} / \mathrm{C}_{5}-\mathrm{S}_{1}$ and $\mathrm{C}_{2}-\mathrm{C}_{3} / \mathrm{C}_{4}-\mathrm{C}_{5}$ bonds elongated. This suggests that if the wave-packet moves initially on the $2{ }^{1} \mathrm{~A}_{1}$ excited state potential energy surface, two decay channels are possible. One is along the totally symmetric $\left(\mathrm{A}_{1}\right)$ reaction coordinates. The other is along the totally symmetric $\left(\mathrm{A}_{1}\right)$ plus nontotally symmetric $\left(B_{1}\right)$ reaction coordinates. Since our $239.5 \mathrm{~nm}$ 

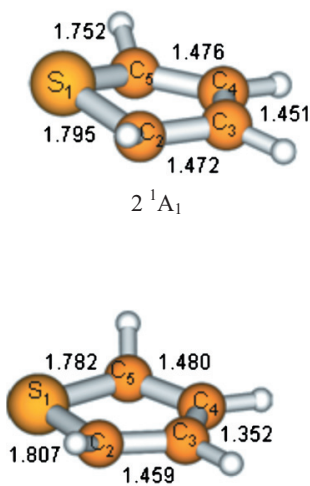

$1{ }^{3} \mathrm{~B}_{2}$

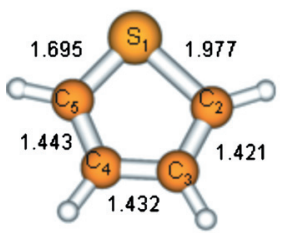

${ }^{1} \mathrm{~B}_{1} /{ }^{1} \mathrm{~A}_{1}$

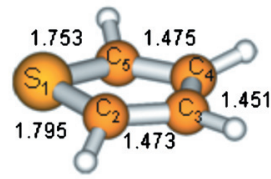

$1{ }^{1} \mathrm{~B}_{2}$

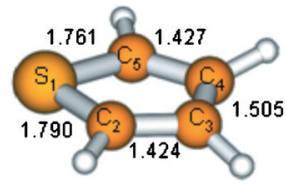

$1{ }^{3} \mathrm{~A}_{1}$

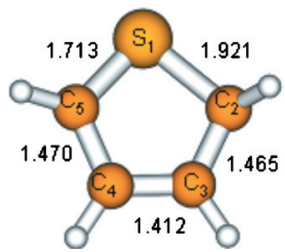

${ }^{1} \mathrm{~B}_{2} /{ }^{1} \mathrm{~A}_{1}$

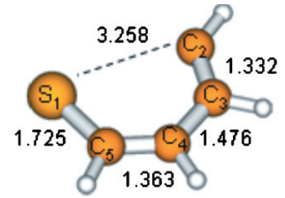

$1{ }^{1} \mathrm{~B}_{1}$

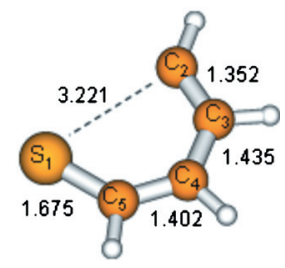

$1{ }^{3} \mathrm{~B}_{1}$

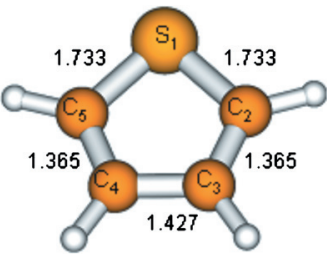

$\mathbf{S}_{\mathbf{0}}$
FIG. 5. $\operatorname{CASSCF}(8,7) / 6-31 \mathrm{G}^{*}$ computed optimized geometry structures of the $2{ }^{1} \mathrm{~A}_{1}, 1{ }^{1} \mathrm{~B}_{2}, 1{ }^{1} \mathrm{~B}_{1}, 1{ }^{3} \mathrm{~B}_{2}$, $1^{3} \mathrm{~A}_{1}$, and $1{ }^{3} \mathrm{~B}_{1}$ excited states and the conical intersection points ${ }^{1} \mathrm{~B}_{1} /{ }^{1} \mathrm{~A}_{1}$ and ${ }^{1} \mathrm{~B}_{2} /{ }^{1} \mathrm{~A}_{1}$ of thiophene. resonance Raman spectrum displays the $\left(\mathrm{A}_{1}+\mathrm{B}_{2}+\mathrm{A}_{2}\right)$ mixed vibrational modes but no $\mathrm{B}_{1}$ symmetric one, the structural dynamics along the pure $2{ }^{1} \mathrm{~A}_{1}$ potential energy surface appears to be ruled out.

The nonadiabatic dynamics in first excited state potential energy hypersurface was recently studied using femtosecond pump probe photoelectron spectroscopy and these results showed that photoexcitation of the $0-0$ level of the A-X transition $\left({ }^{1} \mathrm{~A}_{1} \rightarrow 2{ }^{1} \mathrm{~A}_{1}\right)$ results in the formation of a transient state on the femtosecond time scale $\left(\tau_{1}=80 \pm 10 \mathrm{fs}\right)$ that decays subsequently with a time constant of $\tau_{2}=25 \pm 10 \mathrm{fs}$. ${ }^{31}$ With the aid of DFT/MRCI calculations, the $\tau_{1}=80 \pm 10$ fs process was assigned to the wave-packet motion in first excited state potential energy hypersurface, which relaxes thiophene from the $\mathrm{S}_{0}$ geometry to the $2{ }^{1} \mathrm{~A}_{1}$ minimal struc- ture which is close to the conical intersection point ${ }^{1} \mathrm{~A}_{1} /{ }^{1} \mathrm{~B}_{1}$. The $25 \pm 10$ fs time constant was attributed to an ultrafast decay via a conical intersection to the first excited state potential energy hypersurface, which is a ring opening to the minimum of $1{ }^{1} \mathrm{~B}_{1}$ state that is the global minimum on first excited state potential energy hypersurface. According to our present SA-CASSCF/6-31G* calculations, the minimal energies $\Delta \mathrm{E}(\mathrm{CI})$ of the conical intersections points ${ }^{1} \mathrm{~B}_{1} /{ }^{1} \mathrm{~A}_{1}$ and ${ }^{1} \mathrm{~B}_{2} /{ }^{1} \mathrm{~A}_{1}$ are 6.28 and $6.19 \mathrm{eV}$, respectively, which is very close to $6.30 \mathrm{eV}$ for the vertical transition energy of the $2{ }^{1} \mathrm{~A}_{1}$ state. This suggests that the conical intersections points ${ }^{1} \mathrm{~B}_{1} /{ }^{1} \mathrm{~A}_{1}$ and ${ }^{1} \mathrm{~B}_{2} /{ }^{1} \mathrm{~A}_{1}$ are energetically accessible upon photoexcitation to the $2{ }^{1} \mathrm{~A}_{1}$ state and this is in agreement with previous theoretical studies. ${ }^{23,31,32}$

We note that the structural similarities and differences

TABLE IV. One electron densities of the active orbitals for the conical intersection points ${ }^{1} \mathrm{~B}_{1} /{ }^{1} \mathrm{~A}_{1}$ and ${ }^{1} \mathrm{~B}_{2} /{ }^{1} \mathrm{~A}_{1}$ of thiophene.

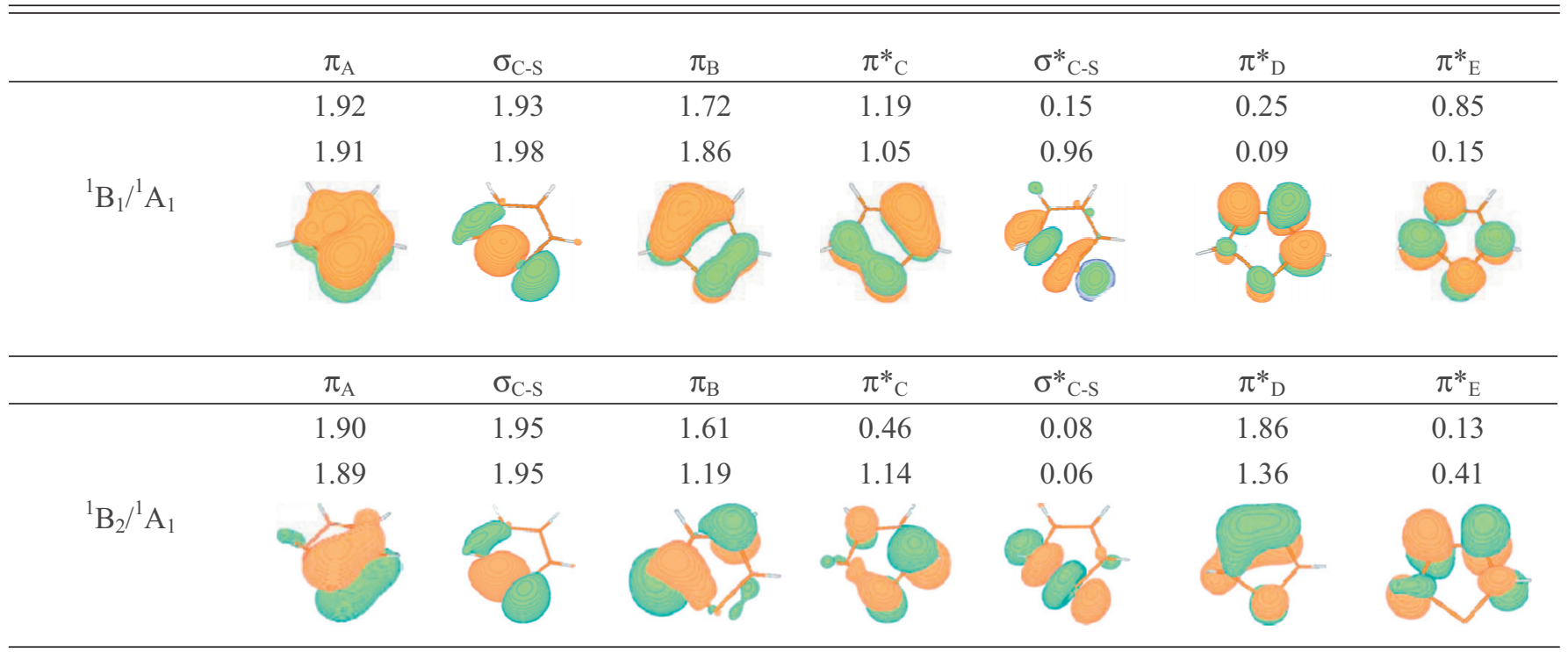



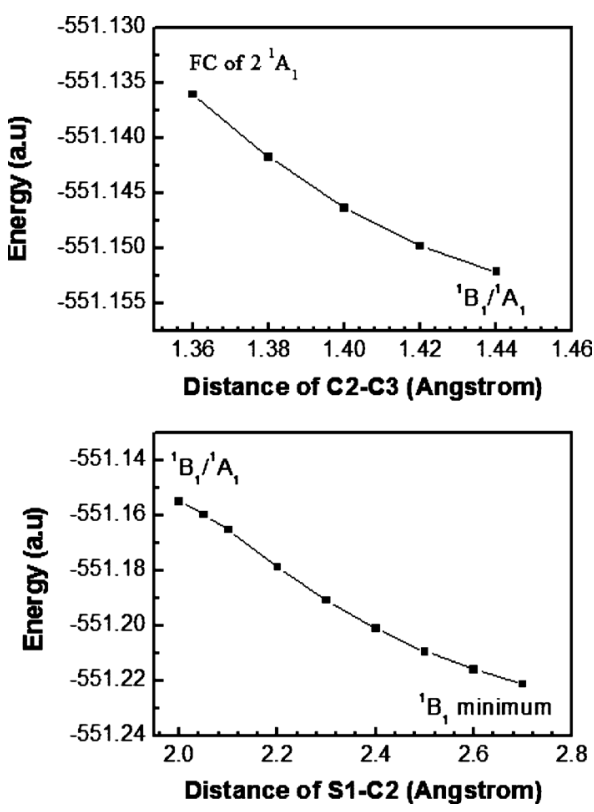

FIG. 6. $\operatorname{CASSCF}(8,7) / 6-31 \mathrm{G}^{*}$ computed minimum energy pathway connecting the Franck-Condon region of the $2{ }^{1} \mathrm{~A}_{1}$ state, the conical intersection point ${ }^{1} \mathrm{~B}_{1} /{ }^{1} \mathrm{~A}_{1}$, and the $1{ }^{1} \mathrm{~B}_{1}$ minimum.

among the optimized structures of the ${ }^{1} \mathrm{~B}_{1} /{ }^{1} \mathrm{~A}_{1},{ }^{1} \mathrm{~B}_{2} /{ }^{1} \mathrm{~A}_{1}$, $1{ }^{1} \mathrm{~B}_{1}, 2{ }^{1} \mathrm{~A}_{1}$, and $\mathrm{S}_{0}$ states provide us with important dynamical information on how the wave-packet evolves on the first excited state potential energy hypersurface. Table III shows that while the bond lengths and bond angles among ${ }^{1} \mathrm{~B}_{1} /{ }^{1} \mathrm{~A}_{1}, 1{ }^{1} \mathrm{~B}_{1}$, and $\mathrm{S}_{0}$ are significantly different, the structures share the ring plane as a common symmetry constraint. This indicates that during the ultrafast decay via the ${ }^{1} \mathrm{~B}_{1} /{ }^{1} \mathrm{~A}_{1}$ conical intersection, thiophene evolves on the first excited state potential energy hypersurface in a way that likely holds the $\mathrm{A}^{\prime}$ irreducible representation. This agrees very well with our $239.5 \mathrm{~nm}$ resonance Raman spectrum that displays predominantly vibrational modes in $\mathrm{A}_{1}$ and $\mathrm{B}_{2}$, which become the $\mathrm{A}^{\prime}$ dynamical symmetry in the excited state potential energy surface due to ${ }^{1} \mathrm{~B}_{1} /{ }^{1} \mathrm{~A}_{1}$ conical intersection, and suggests that when wave-packet initially moves on the first excited state potential energy hypersurface, thiophene will not relax directly to the $2{ }^{1} \mathrm{~A}_{1}$ minimum region, that is the decay channel from the $2{ }^{1} \mathrm{~A}_{1}$ minimum to $1{ }^{1} \mathrm{~B}_{1}$ minimum via ${ }^{1} \mathrm{~B}_{1} /{ }^{1} \mathrm{~A}_{1}$ does not appear to be likely. Since the geometry parameters of the conical intersection point ${ }^{1} \mathrm{~B}_{1} /{ }^{1} \mathrm{~A}_{1}$ are noticeably different from those of the $\mathrm{S}_{0}, 2{ }^{1} \mathrm{~A}_{1}$, and $1{ }^{1} \mathrm{~B}_{1}$ states and the vertical transition energy $\Delta \mathrm{E}(\mathrm{FC})$ of the $2{ }^{1} \mathrm{~A}_{1}$ state is nearly isoenergetic to the minimal energy $\Delta \mathrm{E}(\mathrm{IC})$ of the conical intersection point ${ }^{1} \mathrm{~B}_{1} /{ }^{1} \mathrm{~A}_{1}$, a more likely decay mechanism could be that upon photoexcitation to the FC region of the $2{ }^{1} \mathrm{~A}_{1}$ state the thiophene moves along the $2{ }^{1} \mathrm{~A}_{1}$ surface for a while (but not likely down to the $2{ }^{1} \mathrm{~A}_{1}$ minimum) and then transits from the $2{ }^{1} \mathrm{~A}_{1}$ potential energy surface to the seam of the ${ }^{1} \mathrm{~B}_{1} /{ }^{1} \mathrm{~A}_{1}$ conical intersection $\left(\mathrm{C}_{\mathrm{s}}\right.$ symmetry) and finally moves down to the minimum of the $1{ }^{1} \mathrm{~B}_{1}$ state that is the global minimum of first excited state potential energy hypersurface. Figure 6 presents the $\operatorname{CASSCF}(8,7) / 6-31 \mathrm{G}^{*}$ computed minimum energy pathway connecting $2{ }^{1} \mathrm{~A}_{1}(\mathrm{FC}),{ }^{1} \mathrm{~B}_{1} /{ }^{1} \mathrm{~A}_{1}$, and ${ }^{1} \mathrm{~B}_{1}$. Figure 6 and Table
II shows clearly that this photodissociation reaction pathway constitutes the global minimum on first excited state potential energy hypersurface and is a barrierless process. This prediction is slightly different than the DFT/MRCI prediction that shows a very shallow barrier. Since the intensity pattern of our resonance Raman spectra represents very directly and clearly the FC region structural dynamics that are predominantly toward the structure of the conical intersection point ${ }^{1} \mathrm{~B}_{1} /{ }^{1} \mathrm{~A}_{1}$, where the $\tau_{1}=80 \pm 10$ fs time constant is assigned to the wave-packet motion along the $2{ }^{1} \mathrm{~A}_{1}$ surface for thiophene to reorganize its geometry to reach to ${ }^{1} \mathrm{~B}_{1} /{ }^{1} \mathrm{~A}_{1}$, and the $\tau_{2}=25 \pm 10 \mathrm{fs}$ is attributed to the ring opening process via ${ }^{1} \mathrm{~B}_{1} /{ }^{1} \mathrm{~A}_{1}$ which is likely supported by our present study.

The minimal energy $\Delta \mathrm{E}(\mathrm{IC})$ of the conical intersection point ${ }^{1} \mathrm{~B}_{2} /{ }^{1} \mathrm{~A}_{1}$ is lower than the vertical transition energies $\Delta \mathrm{E}(\mathrm{FC})$ of the $2{ }^{1} \mathrm{~A}_{1}$ state and the minimal energy $\Delta \mathrm{E}$ (IC) of the conical intersection point ${ }^{1} \mathrm{~B}_{1} /{ }^{1} \mathrm{~A}_{1}$ by 2.5 and $2.1 \mathrm{kcal} /$ mol, respectively. The decay pathway to first excited state potential energy hypersurface via ${ }^{1} \mathrm{~B}_{2} /{ }^{1} \mathrm{~A}_{1}$ constitutes the second decay channel and is also likely a barrierless process. We note that while the differences between the minimal energies $\Delta \mathrm{E}$ (IC) of the conical intersection points ${ }^{1} \mathrm{~B}_{2} /{ }^{1} \mathrm{~A}_{1}$ and ${ }^{1} \mathrm{~B}_{1} /{ }^{1} \mathrm{~A}_{1}$ and the vertical transition energy $\Delta \mathrm{E}(\mathrm{FC})$ of the $2{ }^{1} \mathrm{~A}_{1}$ state are not significant, their dynamic correlations are obviously different from one another. The $\mathrm{A}_{2}$ representation character of the geometry structures of the conical intersection point ${ }^{1} \mathrm{~B}_{2} /{ }^{1} \mathrm{~A}_{1}$ and the $1{ }^{1} \mathrm{~B}_{2}$ state suggests that the initial reaction coordinates are along twist or torsional vibrational motions. This is very well supported by our resonance Raman spectrum that also displays a noticeable $\mathrm{H}_{7} \mathrm{C}_{3}-\mathrm{C}_{4} \mathrm{H}_{8}$ twist vibrational mode $\nu_{9}\left(\mathrm{~A}_{2}\right.$ representation) and indicates that the wave-packet initially in the $\mathrm{FC}$ region of ${ }^{1} \mathrm{~A}_{1}$ will move partially to the $1{ }^{1} \mathrm{~B}_{2}$ surface via ${ }^{1} \mathrm{~B}_{2} /{ }^{1} \mathrm{~A}_{1}$. We expect that the decay pathway via ${ }^{1} \mathrm{~B}_{2} /{ }^{1} \mathrm{~A}_{1}$ constitutes a minor channel when compared to that via ${ }^{1} \mathrm{~B}_{1} /{ }^{1} \mathrm{~A}_{1}$ since the resonance Raman intensities of the $\mathrm{B}_{2}$ fundamentals, overtones, and combination bands, which reflect the weight of wave-packet crossing from $2{ }^{1} \mathrm{~A}_{1}$ to $1{ }^{1} \mathrm{~B}_{1}$ via ${ }^{1} \mathrm{~B}_{1} /{ }^{1} \mathrm{~A}_{1}$, are much stronger than those of the $\mathrm{A}_{2}$ fundamentals, overtones, and combination bands. This indicates that the decay channel via ${ }^{1} \mathrm{~B}_{2} /{ }^{1} \mathrm{~A}_{1}$ is dynamically difficulty to access. A likely explanation is that both the conical intersection point ${ }^{1} \mathrm{~B}_{1} /{ }^{1} \mathrm{~A}_{1}$ and the $\mathrm{FC}$ region of the $2{ }^{1} \mathrm{~A}_{1}$ state are at one side of the paraboloid of the $2{ }^{1} \mathrm{~A}_{1}$ potential well, while both the conical intersection point ${ }^{1} \mathrm{~B}_{2} /{ }^{1} \mathrm{~A}_{1}$ and the $\mathrm{FC}$ region of the $2{ }^{1} \mathrm{~A}_{1}$ state are away from each other or possibly they are located at the different side of the paraboloid of the $2{ }^{1} \mathrm{~A}_{1}$ potential well.

We understand that both the lifetime of the interested states and excited state displacements of nuclear coordinates determine the resonance Raman intensity patterns. According to time-dependent wave-packet theory for two state conical intersection, the intensity of each Raman transition depends on the overlap of the wavepacket with a particular, different final state. In general, those modes that undergo the largest excited state geometry changes will exhibit the highest fundamental intensities and longest overtone progressions. In other words the intensities of the first overtones and combi- 
nation bands are mostly determined by the slope of the potential energy surface. The steeper the slope of the potential energy surface, the stronger the intensities of overtones and combination bands. Therefore the relative intensities of the overtones and combination bands $\left(\mathrm{B}_{2}\right.$ vibrational modes versus $\mathrm{A}_{2}$ vibrational modes) are carefully used as evidence of the more important excited state displacement $\left(1{ }^{1} \mathrm{~B}_{1}\right.$ state versus $1{ }^{1} \mathrm{~B}_{2}$ state).

Lifetime is another aspect that will influence but not dominate the intensities of the overtones and combination bands. We have noted that the overall effect of motion of the wavepacket along many vibrational modes is that the wavepacket, once it leaves the neighborhood of the ground state geometry, virtually never returns for truly dissociative potentials, and both the absorption spectrum and the resonance Raman intensities become determined almost entirely by the dynamics occurring in the first tens of femtoseconds. Molecules with bound excited states and only a few displaced modes may have significant overlaps at much longer times. In case of thiophene, the most important excited state dynamics is along the dissociation channel but not the bound one. This ensures that the use of the relative intensities of the overtones and combination bands as evidence of the more important excited state displacement is safe.

\section{E. Discussions of the vibrational assignments relative to nontotally symmetric fundamentals and/or overtones and their dynamical implications}

Herzberg-Teller vibronic-coupling mechanism and the standard A-term mechanism are two rules that are frequently used in the vibrational assignments of some resonance Raman bands relative to nontotally symmetric fundamentals and/or their overtones. The standard A-term mechanism works if the vibrational frequency along that vibrational mode changes between electronically ground and excited states. In this case, the resonance Raman bands, which cannot be assigned as totally symmetric fundamentals and their overtones and combination bands, are assigned to the overtones and/or combination bands of nontotally fundamentals. In contrast, the Herzberg-Teller vibronic-coupling mechanism is used in the case when the resonance Raman bands can only be assigned as the nontotally symmetric fundamentals. In the present paper we try to provide the chemical physics society a new interpretation of the appearance of the nontotally symmetric vibrations in the resonance Raman spectra - the role of the Franck-Condon region conical intersection.

The Franck-Condon region ${ }^{1} \mathrm{~B}_{1} /{ }^{1} \mathrm{~A}_{1}$ conical intersection point is revealed by our CASSCF calculations for thiophene. Potential energy surface scan calculations indicate (see Fig. 6) that because of the ${ }^{1} \mathrm{~B}_{1} /{ }^{1} \mathrm{~A}_{1}$ conical intersection point and the dissociative nature of $1{ }^{1} \mathrm{~B}_{1}$ state (induced by $\pi$ $\rightarrow \sigma_{\mathrm{C}-\mathrm{S}}^{*}$ transition), the potential energy surface of the interested excited state is directly dissociative along the $\mathrm{C}-\mathrm{S}$ antisymmetry stretch reaction coordinate from the FranckCondon region of the $2{ }^{1} \mathrm{~A}_{1}$ state to the minimum geometry structure of $1{ }^{1} \mathrm{~B}_{1}$ state. It is very helpful to note that along this reaction coordinate the molecule holds the Cs point group and the dynamical synmmetry for the excited state will become Cs point group. Therefore the irreducible representations $\mathrm{A}_{1}$ and $\mathrm{B}_{2}$ together (all belong to in-plane vibrations), or $A_{2}$ and $B_{1}$ together (all belong to out-of-plane vibrations) in $\mathrm{C}_{2 \mathrm{~V}}$ point group will transform to the corresponding $\mathrm{A}^{\prime}$ or $\mathrm{A}^{\prime \prime}$ irreducible representation in Cs point group, and all vibrations that have $\mathrm{A}_{1}$ and $\mathrm{B}_{2}$ irreducible representations become dynamically totally symmetric vibrations in terms of Cs point group from FC to the minimum of $1{ }^{1} \mathrm{~B}_{1}$ state. Therefore the appearance of the nominal $\mathrm{C}-\mathrm{S}$ antisymmetry stretch mode $\nu_{21}\left(\mathrm{~B}_{2}\right)$ at $754 \mathrm{~cm}^{-1}$ and $\nu_{18}\left(\mathrm{~B}_{2}\right)$ at $1244 \mathrm{~cm}^{-1}$ are apparently due to the Franck-Condon ${ }^{1} \mathrm{~B}_{1} /{ }^{1} \mathrm{~A}_{1}$ conical intersection point but not because of ${ }^{1} \mathrm{~A}_{1} /{ }^{1} \mathrm{~B}_{2}$ conical intersection since in ${ }^{1} \mathrm{~B}_{2}$ electronic excited state the molecule will change its point group to have $\mathrm{C}_{1}$ point group, which is away from both the $\mathrm{C}_{2 \mathrm{~V}}$ and Cs point groups (see Fig. 5). Therefore the two bands at 754 and $1244 \mathrm{~cm}^{-1}$ are preferentially assigned as $\nu_{21}\left(\mathrm{~B}_{2}\right)$ and $\nu_{18}\left(\mathrm{~B}_{2}\right)$.

The Herzberg-Teller vibronic-coupling mechanism ${ }^{52}$ is well known to be widely used in interpreting the appearance of the nontotally symmetric vibrations (fundamentals) that would be dark in the resonance Raman spectra if without vibronic-coupling. In other words if a dark electronically excited state having a certain irreducible representation couples to a bright state, some vibrations having the corresponding irreducible representation will become active through Raman intensity borrowing from the bright state. In case of thiophene, the A-band absorption of thiophene belongs to $1{ }^{1} \mathrm{~A}_{1} \rightarrow 2{ }^{1} \mathrm{~A}_{1}$ transition. If a two state vibronic-coupling mechanism is applicable, the nearby $1{ }^{1} \mathrm{~B}_{1}$ or ${ }^{1} \mathrm{~B}_{2}$ state will couple to the $2{ }^{1} \mathrm{~A}_{1}$ state, and this would cause the corresponding direct product of the irreducible representations to have $\mathrm{B}_{1}$ or $\mathrm{B}_{2}$ symmetry noting that ${ }^{1} \mathrm{~A}_{1} \times{ }^{1} \mathrm{~B}_{1}={ }^{1} \mathrm{~B}_{1}$ or ${ }^{1} \mathrm{~A}_{1}$ $\times{ }^{1} \mathrm{~B}_{2}={ }^{1} \mathrm{~B}_{2}$, based on the symmetry information in Table II. Since the general rule for transition polarizability tensor to be nonzero is that the product $\Psi_{s} Q_{i} \Psi_{r}$ belongs to a representation which contains the totally symmetric species (here, the subscript $\mathrm{s}$ and $\mathrm{r}$ denote two mutual coupled excited states, $Q_{i}$ is a certain coupling vibrational mode), it comes out immediately that only those vibrational modes that have $B_{1}$ or $\mathrm{B}_{2}$ symmetry will possibly show in the resonance Raman spectra. Apparently assigning, respectively, the 754 and $1244 \mathrm{~cm}^{-1}$ band as $\nu_{21}\left(\mathrm{~B}_{2}\right)$ and $\nu_{18}\left(\mathrm{~B}_{2}\right)$ also meets the $2{ }^{1} \mathrm{~A}_{1}-1{ }^{1} \mathrm{~B}_{2}$ Herzberg-Teller vibronic-coupling mechanism, but its underlying dynamics should be very different than the photodissociation dynamics due to the ${ }^{1} \mathrm{~B}_{1} /{ }^{1} \mathrm{~A}_{1}$ conical intersection.

In term of the $2{ }^{1} \mathrm{~A}_{1}-1{ }^{1} \mathrm{~B}_{2}$ two state vibronic-coupling mechanism, the appearance of the resonance Raman line at 754 or $1244 \mathrm{~cm}^{-1}$, which is assigned as a nontotally symmetric fundamental, $\nu_{21}\left(\mathrm{~B}_{2}\right)$ or $\nu_{18}\left(\mathrm{~B}_{2}\right)$, indicates that the Raman intensity borrowing occurs for the $1{ }^{1} \mathrm{~B}_{2}$ state and suggests that both $2{ }^{1} \mathrm{~A}_{1}$ and $1{ }^{1} \mathrm{~B}_{2}$ states contribute to the $239.5 \mathrm{~nm}$ resonance Raman spectra of thiophene. Since the vibronic-coupling mechanism is likely the case of the avoided crossing between the two or more states, where the excited state wavepacket is not allowed to jump from one surface to another, or one state dominates the excited state dynamics in the interested state while the coupling state per- 
turbs the dynamics, the relative intensities of the totally symmetric modes reflect the relative degrees of the $2{ }^{1} \mathrm{~A}_{1}$ excited state geometry changes along those vibrational modes based on the "A-term" mechanism, while the relative intensities of the nontotally symmetric modes mean the relative intensity borrowings through vibronic-coupling mechanism or the relative coupling strengths between the nontotally vibrations and the two excited states $\left(2{ }^{1} \mathrm{~A}_{1}\right.$ and $\left.1{ }^{1} \mathrm{~B}_{2}\right)$. Thus the strong intensities of $\nu_{21}\left(\mathrm{~B}_{2}\right)$ and its large progressions of the overtones and combination bands cannot be interpreted as the large geometry changes along these modes in the $2{ }^{1} \mathrm{~A}_{1}$ excited state.

The dynamic picture of the appearance of $\nu_{21}\left(\mathrm{~B}_{2}\right)$ or $\nu_{18}\left(\mathrm{~B}_{2}\right)$ in terms of the $2{ }^{1} \mathrm{~A}_{1}-1{ }^{1} \mathrm{~B}_{2}$ two state vibroniccoupling mechanism is very different than that in terms of the Franck-Condon region ${ }^{1} \mathrm{~B}_{1} /{ }^{1} \mathrm{~A}_{1}$ conical intersection mechanism. According to the wavepacket theory of two state conical intersection, ${ }^{53}$ the excited state wavepacket is allowed to jump from one surface to another. This means that the relative intensities of both the totally and nontotally symmetric modes $\left(A_{1}\right.$ and $B_{2}$ irreducible in term of ground state symmetry) reflect the degrees of the excited state geometry changes along those vibrational modes $\left(\mathrm{A}^{\prime}\right.$ irreducible in terms of dynamical symmetry) when the Franck-Condon region ${ }^{1} \mathrm{~B}_{1} /{ }^{1} \mathrm{~A}_{1}$ conical intersection works. Apparently all $\mathrm{B}_{2}$ vibrations in term of ground state symmetry become dynamically symmetry in the $\mathrm{A}^{\prime}$ excited state potential energy surface and the A-term mechanism works for both the $A_{1}$ and $\mathrm{B}_{2}$ vibrational fundamentals.

It is well known that the Born-Oppenheimer approximation becomes invalid in the vicinity of the conical intersection. Thus the Herzberg-Teller vibronic-coupling, which is derived from the Born-Oppenheimer approximation, lapses in the vicinity of the Franck-Condon region ${ }^{1} \mathrm{~B}_{1} /{ }^{1} \mathrm{~A}_{1}$ conical intersection point. Therefore that the intense resonance $\mathrm{Ra}$ man intensities appear for the $\mathrm{C}-\mathrm{S}$ antisymmetry stretch $\nu_{21}\left(\mathrm{~B}_{2}\right)$ at $754 \mathrm{~cm}^{-1}$ and the $\mathrm{C}-\mathrm{H}$ antisymmetry in-plane wag $\nu_{18}\left(\mathrm{~B}_{2}\right)$ at $1244 \mathrm{~cm}^{-1}$ could be an indication that large geometry change occurs simultaneously with an electron transition from $2{ }^{1} \mathrm{~A}_{1}$ state to $1{ }^{1} \mathrm{~B}_{2}$ state. From this point of view, the vibrational assignments of the two bands at 754 and $1244 \mathrm{~cm}^{-1}$ as $\nu_{21}\left(\mathrm{~B}_{2}\right)$ and $\nu_{18}\left(\mathrm{~B}_{2}\right)$ must be based on the mechanism of the Franck-Condon region ${ }^{1} \mathrm{~B}_{1} /{ }^{1} \mathrm{~A}_{1}$ conical intersection and the Herzberg-Teller vibronic-coupling mechanism is ruled out.

${ }^{1} \mathrm{~B}_{2} /{ }^{1} \mathrm{~A}_{1}$ conical intersection is also predicted by the present study. The decay pathway to first excited state potential energy hypersurface via ${ }^{1} B_{2} /{ }^{1} A_{1}$ constitutes the second decay channel and is also likely a barrierless process. Therefore the $906 \mathrm{~cm}^{-1}$ band is preferentially assigned as $\nu_{9}\left(\mathrm{~A}_{2}\right)$ vibration since this vibration is an important reaction coordinate for thiophene to reach the optimized geometric structure of the $1{ }^{1} \mathrm{~B}_{2}$ state through the Franck-Condon region ${ }^{1} \mathrm{~B}_{2} /{ }^{1} \mathrm{~A}_{1}$ conical intersection point.

The standard A-term mechanism is also successfully applied in many publications for the assignments of some resonance Raman bands as the even overtones of nontotally symmetric vibrations. Therefore an alternative assignment of the $1244 \mathrm{~cm}^{-1}$ band, which cannot be assigned as the totally symmetry fundamental, could be a combinational vibration $\nu_{10}\left(\mathrm{~A}_{2}\right)+\nu_{11}\left(\mathrm{~A}_{2}\right)$, which is totally symmetric and is predicted at $1248 \mathrm{~cm}^{-1}$ based on the frequencies given in Table I. Similarly, 906 and $1134 \mathrm{~cm}^{-1}$, which cannot be assigned as the totally symmetry fundamentals (in terms of the electronically ground state), could be, respectively, assigned as the $2 \nu_{14}\left(\mathrm{~B}_{1} \times \mathrm{B}_{1}\right)$ and $2 \nu_{11}\left(\mathrm{~A}_{2} \times \mathrm{A}_{2}\right)$.

\section{CONCLUSION}

In this paper we report for the first time a combined resonance Raman spectroscopy and complete active space self-consistent field theory computational study of the FC region structural dynamics and conical intersections of thiophene. The FT-Raman in neat liquid and the 266 and $239.5 \mathrm{~nm}$ resonance Raman spectra in cyclohexane solution were measured and the vibrational assignments are done for the spectra. The results indicate that the Franck-Condon region structural dynamics are multidimensional in nature with the motions mainly along the reaction coordinates of the $\mathrm{C}_{2}=\mathrm{C}_{3}-\mathrm{C}_{4}=\mathrm{C}_{5}$ in-plane symmetric stretch modes $\nu_{3}\left(\mathrm{~A}_{1}\right)$ and $\nu_{4}\left(\mathrm{~A}_{1}\right)$, the $\mathrm{C}-\mathrm{S}$ antisymmetry stretch mode $\nu_{21}\left(\mathrm{~B}_{2}\right)$, the $\mathrm{C}-\mathrm{S}$ in-plane wag mode $\nu_{18}\left(\mathrm{~B}_{2}\right)$, the $\mathrm{H}_{7} \mathrm{C}_{3}-\mathrm{C}_{4} \mathrm{H}_{8}$ twist $\nu_{9}\left(\mathrm{~A}_{2}\right)$, and other four totally symmetry modes of $\nu_{5}\left(\mathrm{~A}_{1}\right), \nu_{6}\left(\mathrm{~A}_{1}\right), \nu_{7}\left(\mathrm{~A}_{1}\right)$, and $\nu_{8}\left(\mathrm{~A}_{1}\right)$. To gain some insight into the dynamical nature of the appearance of $\nu_{21}\left(\mathrm{~B}_{2}\right)$, $\nu_{18}\left(\mathrm{~B}_{2}\right)$, and $\nu_{9}\left(\mathrm{~A}_{2}\right)$, the optimized geometry structural parameters of the low-lying excited states $2{ }^{1} \mathrm{~A}_{1}, 1{ }^{1} \mathrm{~B}_{2}, 1{ }^{1} \mathrm{~B}_{1}$, $1{ }^{3} \mathrm{~B}_{2}, 1{ }^{3} \mathrm{~A}_{1}$, and $1{ }^{3} \mathrm{~B}_{1}$, as well as the conical intersection points ${ }^{1} \mathrm{~B}_{1} /{ }^{1} \mathrm{~A}_{1}$ and ${ }^{1} \mathrm{~B}_{2} /{ }^{1} \mathrm{~A}_{1}$ between the $1{ }^{1} \mathrm{~B}_{1}, 1{ }^{1} \mathrm{~B}_{2}$, and $2{ }^{1} \mathrm{~A}_{1}$ potential energy surfaces of thiophene, have been determined by employing the CASSCF method. The unconstrained geometry optimization of thiophene in the $2{ }^{1} \mathrm{~A}_{1}$ and ${ }^{1} \mathrm{~B}_{2}$ states yield the distorted structures with the $\mathrm{S}$ atom being bent out-of-plane, while that in the $1{ }^{1} \mathrm{~B}_{1}$ state results in one $\mathrm{C}-\mathrm{S}$ bond breaking with a $\mathrm{Cs}$ point group being held. The CASSCF/6-31G ${ }^{*}$ calculated ${ }^{1} \mathrm{~B}_{1} /{ }^{1} \mathrm{~A}_{1}$ structure and $\mathrm{C}-\mathrm{S}$ bond breaking nature of thiophene in the $1{ }^{1} \mathrm{~B}_{1}$ state are well correlated with the appearance of the $\mathrm{C}-\mathrm{S}$ antisymmetry stretch mode $\nu_{21}\left(\mathrm{~B}_{2}\right)$ in $239.5 \mathrm{~nm}$ resonance Raman spectrum, while the calculated distorted geometry structures of the conical intersection point ${ }^{1} \mathrm{~B}_{2} /{ }^{1} \mathrm{~A}_{1}$ and the ${ }^{1}{ }^{1} \mathrm{~B}_{2}$ state are well correlated with the appearance of the $\mathrm{C}-\mathrm{S}$ antisymmetry stretch mode $\nu_{9}\left(\mathrm{~A}_{2}\right)$. The determination of the conical intersection point ${ }^{1} \mathrm{~B}_{1} /{ }^{1} \mathrm{~A}_{1}$ provides evidence that the ultrafast ring opening photodissociation reaction via one $\mathrm{C}-\mathrm{S}$ bond breaking is due to the $\mathrm{FC}$ region curvecrossing between the $1{ }^{1} \mathrm{~B}_{1}$ and $2{ }^{1} \mathrm{~A}_{1}$ potential energy surfaces. The CASSCF/6-31G ${ }^{*}$ calculated minimum energy pathway between the FC region and the final geometry of the ring opening product indicates the ring opening reaction is barrierless toward the global minimum of the first excited state potential energy hypersurface and is the major decay channel. Similarly the internal conversion via the conical intersection point ${ }^{1} \mathrm{~B}_{2} /{ }^{1} \mathrm{~A}_{1}$ is away from the $\mathrm{FC}$ region of the $2{ }^{1} \mathrm{~A}_{1}$ state or probably the $\mathrm{FC}$ region of the $2{ }^{1} \mathrm{~A}_{1}$ state and the conical intersection point ${ }^{1} \mathrm{~B}_{2} /{ }^{1} \mathrm{~A}_{1}$ are located at the different sides of the paraboloid of the $2{ }^{1} \mathrm{~A}_{1}$ potential well, and the decay pathway is evidently a minor channel. The vibra- 
tional assignments relative to nontotally symmetric fundamentals and/or overtones and their dynamical implications are discussed. A new interpretation of the appearance of the nontotally symmetric fundamental vibrations in the resonance Raman spectra based on the Franck-Condon region conical intersection is achieved.

\section{ACKNOWLEDGMENTS}

This work was supported by grants from the National Basic Research Program of China (Grant No. 2007CB815203), NSFC (Grant Nos. 21033002, 20573097, and 20703038), NSFZJ (Grant No. R405465) to X.M., and from the Research Grants Council (RGC) of Hong Kong (HKU 7039/07P) to D.L.P. D.L.P. thanks the Croucher Foundation for the award of a Croucher Foundation Senior Research Fellowship (2006-2007) and the University of Hong Kong for an Outstanding Researcher Award (2006). X.Z. wishes to acknowledge the referees for their contributions in making this a better paper.

${ }^{1}$ H. D. Hartough, The Chemistry of Heterocyclic Compounds (WileyInterscience, New York, 1952), Vol. 3; S. Gronowitz, The Chemistry of Heterocyclic Compounds (Wiley-Interscience, New York, 1992), Vol. 44; R. A. Jones, The Chemistry of Heterocyclic Compounds (Wiley, New York, 1992), Vol. 48; Conjugated Polymers: The Novel Science and Technology of Highly Conducting and Nonlinear Optically Active Materials, edited by J. L. Brédas and R. Silbey (Kluwer, Dordrecht, 1991).

${ }^{2}$ A. B. Trofimov, H. Köppel, and J. Schirmer, J. Chem. Phys. 109, 1025 (1998); E. V. Gromov, A. B. Trofimov, N. M. Vitkovskaya, J. Schirmer, and H. Köppel, ibid. 119, 737 (2003).

${ }^{3}$ L. Trouillet, M. Lapkowski, O. Stephan, and S. Guillerez, Synth. Met. 109, 277 (2000).

${ }^{4}$ V. Coropceanu, O. Kwon, B. Wex, B. R. Kaafarani, N. E. Gruhn, J. C. Durivage, D. C. Neckers, and J. L. Brédas, Chem.-Eur. J. 12, 2073 (2006).

${ }^{5}$ M. C. R. Delgado, V. Hernández, J. Casado, J. T. Navarrete, L. J. Raimundo, M. P. Blanchard, and J. Roncali, Chem.-Eur. J. 9, 3670 (2003).

${ }^{6}$ Y. Feng, Y. Yan, S. Wang, W. Zhu, S. Qian, and H. E. Tian, J. Mater. Chem. 16, 3685 (2006)

${ }^{7}$ W. C. Price and A. D. Walsh, Proc. R. Soc. London, Ser. A 179, 201 (1941).

${ }^{8}$ G. D. Lonardo, G. Galloni, A. Trombetti, and C. Zauli, J. Chem. Soc., Faraday Trans. 2 68, 2009 (1972).

${ }^{9}$ G. L. Bendazzoli, F. Bertinelli, and P. Palmieri, J. Chem. Phys. 69, 5077 (1978).

${ }^{10}$ G. Varsányi, L. Nyulászi, T. Veszprémi, and T. Narisawa, J. Chem. Soc., Perkin Trans. 2 1982, 761 (1982).

${ }^{11}$ L. Nyulászi and T. Veszprémi, J. Mol. Struct. 140, 353 (1986).

${ }^{12}$ L. Nyulászi and T. Veszprémi, J. Mol. Struct. 140, 253 (1986).

${ }^{13}$ L. Nyulászi and T. Veszprémi, Chem. Scr. 28, 331 (1988).

${ }^{14}$ B. Norden, R. Hakansson, P. B. Pedersen, and E. W. Thulstrup, Chem. Phys. 33, 355 (1978).

${ }^{15}$ N. Igarashi, A. Tajiri, and M. Hatano, Bull. Chem. Soc. Jpn. 54, 1511 (1981).

${ }^{16}$ W. M. Flicker, O. A. Mosher, and A. Kuppermann, Chem. Phys. Lett. 38, 489 (1976).

${ }^{17}$ W. M. Flicker, O. A. Mosher, and A. Kuppermann, J. Chem. Phys. 64, 1315 (1976).

${ }^{18}$ E. H. Van Veen, Chem. Phys. Lett. 41, 535 (1976).

${ }^{19}$ M. H. Palmer, I. C. Walker, and M. F. Guest, Chem. Phys. 241, 275
(1999).

${ }^{20}$ S. Rentsch, J. P. Yang, W. Paa, E. Birckner, J. Schiedt, and R. Weinkauf, Phys. Chem. Chem. Phys. 1, 1707 (1999).

${ }^{21}$ H. Haberkern, K. R. Asmis, and P. Swiderek, Phys. Chem. Chem. Phys. 5, 827 (2003)

${ }^{22}$ L. Serrano-Andres, M. Merchan, M. Fulscher, and B. O. Roos, Chem. Phys. Lett. 211, 125 (1993); M. Rubio, M. Merchan, E. Orti, and B. O. Roos, J. Chem. Phys. 102, 3580 (1995).

${ }^{23}$ S. Salzmann, M. Kleinschmidt, J. Tatchen, R. Weinkauf, and C. M. Marian, Phys. Chem. Chem. Phys. 10, 380 (2008).

${ }^{24}$ W. C. Price and A. D. Walsh, Proc. R. Soc. London, Ser. A 170, 201 (1941).

${ }^{25}$ M. D'Auria, A. De Mico, F. D’Onofrio, D. Mendola, and G. Piancatelli, J. Photochem. Photobiol., A 47, 191 (1989); M. D'Auria, J. Photochem. Photobiol., A 91, 187 (1995); CRC Handbook of Organic Photochemistry and Photobiology, 2nd ed., edited by W. M. Horspool and F. Lenci (CRC, Boca Raton, FL, 2004), Chap. 37.

${ }^{26}$ F. Elisei, L. Latterini, G. G. Aloisi, and M. D’Auria, J. Phys. Chem. 99, 5365 (1995).

${ }^{27}$ M. D'Auria, E. De Luca, G. Mauriello, R. Racioppi, and G. Sleiter, J. Chem. Soc., Perkin Trans. 1 1997, 2369 (1997).

${ }^{28}$ K. Oda, H. Tsujita, K. Ohno, and M. Machida, J. Chem. Soc., Perkin Trans. 1 1995, 2931 (1995).

${ }^{29}$ M. D'Auria, J. Photochem. Photobiol., A 149, 31 (2002).

${ }^{30}$ Y.-X. Wang, Y.-S. Chen, and S. Ye, Chem. J. Chin. Iniv. 26, 747 (2005).

${ }^{31}$ R. Weinkauf, L. Lehr, W. Schlag, E. S. Salzmann, and C. M. Marian, Phys. Chem. Chem. Phys. 10, 393 (2008).

${ }^{32}$ H. Köppel, E. V. Gromov, and A. B. Trofimov, Chem. Phys. 304, 35 (2004).

${ }^{33}$ W. M. Kwok and D. L. Phillips, J. Chem. Phys. 104, 2529 (1996); X. Zheng and D. L. Phillips, ibid. 108, 5772 (1998).

${ }^{34}$ X. Zheng, Y. L. Li, and D. L. Phillips, J. Phys. Chem. A 108, 8032 (2004).

${ }^{35}$ X. M. Zhu, S. Q. Zhang, X. Zheng, and D. L. Phillips, J. Phys. Chem. A 109, 3086 (2005).

${ }^{36}$ K. F. Weng, Y. Shi, X. Zheng, and D. L. Phillips, J. Phys. Chem. A 110, 851 (2006).

${ }^{37}$ A. B. Myers, in Laser Techniques in Chemistry, edited by A. B. Myers and T. R. Rizzo (Wiley, New York, 1995), p. 325.

${ }^{38}$ A. Becke, J. Chem. Phys. 84, 4524 (1986).

${ }^{39}$ C. Lee, W. Yang, and R. G. Parr, Phys. Rev. B 37, 785 (1988).

${ }^{40}$ D. Hegarty and M. A. Robb, Mol. Phys. 38, 1795 (1979).

${ }^{41}$ M. J. Frisch, G. W. Trucks, H. B. Schlegel et al., GAUSSIAN 03, Revision B.02, Gaussian, Inc., Pittsburgh PA, 1998, 2003.

${ }^{42}$ M. Rico, J. M. Orza, and J. Morcillo, Spectrochim. Acta 21, 689 (1965).

${ }^{43}$ E. D. Simandiras, N. C. Handy, and R. D. Amos, J. Phys. Chem. 92, 1739 (1988)

${ }^{44}$ A. A. El-Azhary and R. H. Hilal, Spectrochim. Acta, Part A 53, 1365 (1997).

${ }^{45}$ J. M. Orza, M. Rico, and F. Biarge, J. Mol. Spectrosc. 19, 188 (1966); D. W. Scott, ibid. 31, 451 (1969); 37, 77 (1971); J. Bánki, F. Billes, and A. Grofcsik, Acta Chim. Hung. 116, 283 (1984).

${ }^{46}$ D. A. Long, The Raman Effect: A Unified Treatment of the Theory of Raman Scattering by Molecules (Wiley, New York, 2002), p. 249.

${ }^{47}$ W. H. Henneker, A. P. Penner, W. Siebrand, and M. Z. Zgierski, J. Chem. Phys. 69, 1704 (1978).

${ }^{48}$ A. B. Myers, M. O. Trulson, and R. A. Mathies, J. Chem. Phys. 83, 5000 (1985).

${ }^{49}$ J. Quenneville and T. J. Martínez, J. Phys. Chem. A 107, 829 (2003).

${ }^{50}$ P. J. Reid, A. P. Esposito, C. E. Foster, and R. A. Beckman, J. Chem. Phys. 107, 8262 (1997).

${ }^{51}$ M. J. Frisch, I. N. Ragazos, M. A. Robb, and H. B. Schlegel, Chem. Phys. Lett. 189, 524 (1992).

${ }^{52}$ D. J. Swanton, G. B. Bacskay, and N. S. Hush, Chem. Phys. 83, 69 (1984).

${ }^{53}$ P. D. Chowdary and S. Umapathy, J. Raman Spectrosc. 39, 1538 (2008). 